Part 6. IAU structures and organization 


\title{
The IAU, from Commissions to Divisions... to Commissions
}

\author{
Thierry Montmerle $\mathrm{e}^{1,2}$ \\ ${ }^{1}$ Institut d'Astrophysique de Paris, France \\ ${ }^{2}$ Past IAU General Secretary, 2012-2015 \\ email: montmerle@iap.fr
}

\begin{abstract}
This paper tells the story behind the succession of reforms that, for the last twenty years, progressively brought the IAU in line with the fast developments of astronomy and the public awareness of the sky worldwide. One major difficulty was how to organize the scientific activities of an exponentially growing population of astronomers, from 200 at its creation in 1919, in the aftermath of WW I, to over 13500 a century later. The first attempts at "restructuring the IAU", as the expression went, can be dated back to the 1988-1991 triennium. As shown by the Minutes of the successive meetings of the Executive Committee, the attempted strategy was to encourage and even propose Commission mergers, but this policy met with strong opposition, even though a need for change was felt increasingly necessary. The new approach proposed by L. Woltjer, then incoming IAU President, during the 1994 General Assembly at The Hague, was to retain the existing Commissions (along with their Working Groups) but grouping them, more or less topically, into a dozen Divisions. Putting an end to the Commission merger deadlock, this new structure was adopted very quickly, and confirmed at the following GA in Kyoto (1997). But even after this restructuring, there was little evolution of the Commissions, and in some areas the scientific classification and breakdown of the IAU activities reflected by Divisions became questionable. As a result, a new reform was undertaken in 2009, based on a more global approach, but keeping the Division/Commission/Working Group three-tier structure as the backbone of the reforming efforts. Thanks to a close collaboration between the Executive Committee and the Division Presidents, the Divisions were first redefined and approved at the Beijing GA in 2012, followed by a historic, full-fledged "Commission reset", itself approved at the Honolulu GA in 2015. This marked the end of a structure created almost a century before, at the foundation of the IAU: the Standing Committees, precursors to the Commissions. But in response to a Call for Proposals issued by the Executive Committee, the "reset" gave birth to a whole new Commission structure, conceived by the community itself.
\end{abstract}

Keywords. Standing Committees, Commissions, Divisions, Working Groups; National Members, individual members; Executive Committee

\section{Initial conditions: A hundred years ago, the birth the IAU and its difficult political context}

Almost exactly one hundred years ago at the time of writing, on Nov. 11, 1918, at 5:15 am, the armistice was signed between Marshal F. Foch, French supreme commander of the Allied forces, flanked by British and French high-ranking officers, and M. Erzberger, a plenipotentiary civilian representing the German government (a Republic created only two days before), assisted by military advisers. The location was the restaurant-car of a train parked in an isolated railway track, away from the press and the public, in a forest near Compiègne, about $100 \mathrm{~km}$ north of Paris. The armistice took effect at 11 am the same day - triggering bell-ringing and celebrations in every town and village in France, although not in Belgium, which was officially liberated only on Nov. 28. (The two other 


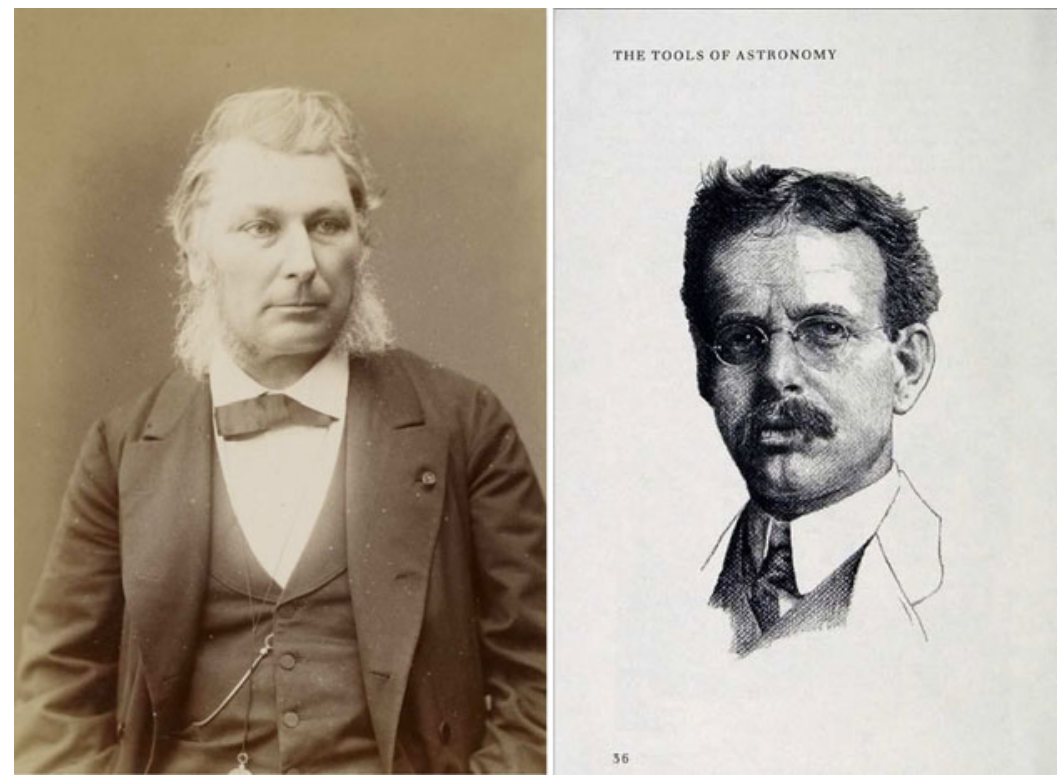

Figure 1. Left: Ernest Mouchez (1821-1892; here in 1883, photographed by Eugène Pirou). Director of the Paris Observatory and Academician, he would launch in 1887 the first world-wide collaboration in astronomy, the Carte du Ciel (charting the sky and cataloguing the stars using photographic plates). Right: George Ellery Hale (1868-1938). American solar astronomer, he founded another pioneering international collaboration, the International Union for Cooperation in Solar Research, in 1904. In many ways, he can be considered as the "father" of the international cooperation in science after WW I, and in particular of the IAU, as described in the text (see Blaauw 1994). Portrait sketch (here in 1913) by Jon R. Friedman, commissioned by Norton Press for "The Astronomer's Universe" (H. Friedman, 1990).

western neighbours of Germany, the Netherlands and Denmark, were neutrals.) Thus, "La Grande Guerre" (The Great War) was ended at last, leaving over 10 million casualties worldwide; silence and peace reappeared in the French and Belgian countrysides devastated by nearly one billion bombshells. Science and technology had developed at incredible speed and contributed enormously, and for the first time in history on such a large scale, to the war effort. $\dagger$ But the worst was yet to come, although of a different nature: in 1918 and 1919, at least 50 million lives worldwide were taken by the so-called "Spanish influenza", maybe coming from China via the USA, and likely spreading quickly across Europe following troop movements to the front and back.

It was in this climate of death and desolation that the IAU was born in Brussels, on July 28, 1919, in the aftermath of the Versailles Treaty, signed on June 28, which aimed at organizing the post-war world and the future founding of the League of Nations (1920). But the astronomers had not been waiting for the end of the war to realize how important international cooperation in science was; in fact they had already experienced it, and the establishment of the IAU was rather a new start after a long and difficult process initiated for scientific, not political, reasons decades before. (For details on the early history of the IAU, a major reference is the book by Blaauw 1994); for more details on the pre-IAU period, see $\mathrm{V}$. Trimble, this volume.)

In 1887, a French rear-admiral, Ernest Amédée Mouchez (Fig. 1a), then Director of Paris Observatory, after having had discussions with the French Académie des Sciences

$\dagger$ To give an idea, nearly 200000 aircraft engines were built between 1914 and 1918 by the belligerents. 
(of which he was a member), embarked on a Herculean project: charting the whole sky and cataloging the stars based on photographic plates. This was the Carte du Ciel project (Lamy 2006; Daston 2017). On paper, 22000 plates of $2^{\circ}$ on each side would do the job. Mouchez initially gathered 18 observatories worldwide (although the USA did not participate), aiming at a completion in about fifteen years. Eventually, difficulties of all sorts, not quite unexpected in view of the diversity of the countries involved across all continents and both hemispheres (including technical, financial, political, communications, etc.) delayed the project (see B. García, this volume, for an account of the situation in Argentina). The work lasted for decades, and the project was terminated but unfinished in 1970, almost a century after its inception, yet leaving a catalogue of over 4 million stars down to 11.5 mag. In 1914, the project had already had its ups and downs, but continued as a leading international cooperative scientific project, to be incorporated into the IAU structure at the end of the war (see below).

Along similar lines, one can also mention the creation in 1906 of the International Committee on Selected Areas, by Jacobus Kapteyn, a famous Deutch astronomer and Professor at the University of Groningen. However, his approach was not to survey and catalogue the whole sky, but to concentrate on "Selected Areas" of the galactic plane for the study of faint stars, to be observed by about 20 telescopes around the world (this time including American institutions, Harvard and Mount Wilson). The project came to fruition only after the war, eventually leading to the Durchmusterung catalogues.

While the Carte du Ciel was a "night sky" global project, the other obvious topic of international collaboration in astronomy was the Sun, a "daytime" global project. However, similar to the Carte $d u$ Ciel, launching a large international collaboration was not simple and required a man of strong influence and dedication: such was George Ellery Hale (Fig. 1b), an American and world leader in solar astronomy, who had studied both in America and in Europe (in Berlin, in fact), and who, as discussed below, would exert an enormous influence on the international organization of science after the war, well beyond astronomy. While Mouchez's collaborative approach was purely about observations, Hale's approach was more institutional. According to Adams (1949), after a wide consultation with colleagues at home and abroad, at his initiative the US National Academy of Sciences invited the leading European academies and scientific societies to send representatives to discuss forming an organization dedicated to coordinating solar research. The occasion was a meeting of the International Congress of Arts and Science, organized in St. Louis along with the 1904 Universal Exposition (itself held in conjunction with the Olympic Games, the first to be held outside Europe): quite an appropriate showcase for an international collaborative spirit - the Spirit of St. Louis, so to speak. .. Seventeen countries were represented, and a committee was appointed to draft the statutes of the International Union for Cooperation in Solar Research, for adoption at a subsequent meeting; the approval of the International Association of Academies was also sought. This meeting took place the following year in Oxford, England, on September 27, 1905, adopting the statutes and even admitting additional countries. Subsequent meetings were held in Meudon (France, 1907), Mount Wilson (USA, 1910), and Bonn (Germany, 1913). Starting at the Mount Wilson meeting, and following Hale's scientific vision, stellar research was also included in the purview of the organization.

Then, the outbreak of the war put an end to all international meetings - and all international organizations were disbanded.

Meanwhile, in view of the inevitable American war effort to come, Hale had been instrumental in the creation of the US National Research Council in April 1916, aimed at stimulating and coordinating the contribution of academia and industry across the country. After the armistice, the NRC was established permanently under the supervision of the National Academy of Sciences, with Hale as Chairman. In this capacity, and also 
as Foreign Secretary of the NAS, Hale pushed a proposal to create an "International Organization of Science and Research", first adopted by the NAS, and discussed with the scientific bodies of the Allied countries, in particular with the Académie des Sciences in Paris and the Royal Society in London.

After much exchange of correspondence and opinions, this initiative led to the organization of the "First Inter-Allied Conference on the Future of International Organization in Science", held in London, at the seat of the Royal Society in Burlington House, during Oct. 9-12, 1918 - so even before the armistice was signed. The participating countries were Belgium, Brazil, France, Great Britain, Italy, Japan, Portugal, Serbia and the USA. In addition to Hale, many astronomers were present, mostly from Belgium, France, Great Britain and the USA. A Resolution was voted to set up a Committee "appointed to prepare a comprehensive plan of international organization in Science", in conformity with Hale's views. But, pressed by Belgium and France, which had suffered the most from the war over their national territories, a Resolution stated that the membership of this organization "shall be restricted to the nations at war with the Central Powers $\dagger$, with the understanding that after the war other nations may be included".

While "other nations" were understood at first as the neutral nations (such as The Netherlands or Spain), in the mind of Hale this also meant, in a perhaps more distant future, the ex-Central Powers. But Belgium and France continued to express fierce opposition, which would subside only a decade later - but this would be to no avail, since by then German and Austrian scientists refused, or were forced to refuse to adhere to the new organization. This was a situation which also left scars within the IAU.

In any case, the ball started to roll fast. Only six weeks after the London meeting, on Nov. 26-29, 1918 (hence after the armistice had been signed), the Second Inter-Allied Conference took place in Paris. Here, following the London Resolution, the new organization appointed a Committee under the name: The International Research Council. Its composition strictly respected the balance of the main Allied powers: Emile Picard, President (France, mathematician and Permanent Secretary of the Académie des Sciences, who had lost a son in the war), G.E. Hale (USA, astronomer), Georges Lecointe (Belgium, Navy officer and astronomer), Vito Volterra (Italy, mathematician), Vice-Presidents; Arthur Schuster (Great Britain, physicist and astrophysicist, Secretary of the Royal Society), General Secretary. Interestingly, Hale, the "father" of the IRC, had only a Vice-President seat. Thus, not only was astronomy well represented in the IRC, but, thanks to Hale, it had played a key role in its inception. (More details on this period can be found in D. DeVorkin, this volume.)

The Third Inter-Allied Conference took place in Brussels, in the Palais des Académies, on July 18-28, 1919, under the patronage of King Albert I of Belgium. The main goal of this Conference, held just one month after the signature of the Versailles Treaty, was to approve the statutes of the IRC, prepared by its Executive Committee appointed in Paris, and that of its first member Unions, among them the IAU. The IAU statutes were adopted on July 26, in fact before the IRC statutes, which were formally adopted on July 28, the last day of the Conference. (That is why July 28, rather than July 26, is considered as the founding date of the IAU.) The IRC itself was created for a period of twelve years, renewable after review. Of course, many consultations had been held before the start of the Brussels Conference, because other issues were to be discussed in advance, among them the problem of the admission of neutral countries (which revealed dissenting views about which countries had been really "neutral" and how, and how fast, they would be allowed to join). The IAU came to life by way of constituting its first Executive Committee, and by establishing at the same time "Standing Committees", the precursors of its Commissions.

$\dagger$ i.e., Germany, Austria and their allies. 
The first IAU Executive Committee more or less respected the political (im)balance of the times. Its composition was: Benjamin Baillaud (France), President; Alfred Fowler (Great Britain), General Secretary; and as Vice-Presidents: William W. Campbell (USA), Frank Dyson (Great Britain), Georges Lecointe (Belgium; also member of the IRC), and Annibale Riccò (Italy; who unfortunately passed away on Sep.23, 1919, so was replaced by Antonio Abetti). Its main task was to get the IAU started and organize its first General Assembly in Rome three years later. (For more details on B. Baillaud, see J.-L. Bougeret, this volume.)

\section{Science at last: structuring the IAU, the origin of Commissions (1919-1922)}

In the background, and in parallel with the preparations of the IRC, astronomers, at that time led like the IRC by the USA, France and Great Britain and their Academies, were working so that their scientific Union, the International Astronomical Union (with French and English as its official languages) could be established not only at the same time as its founding body (the IRC), by way of setting up an Executive Committee, but also be ready to start organizing international research in astronomy immediately, pending formal approval of its structures at its first General Assembly, three years later.

However, the "international" qualifier did not reflect the geographical reality at that time: as mentioned above, the IRC statutes de facto excluded ex-Central Power countries from being affiliated, not only to its own organization, but also to that of its member Unions, and neutral countries could be admitted only after a three-quarter majority vote of that Union. These restrictive conditions, perhaps understandable on the short term, quickly created an atmosphere of suspicion and animosity among scientists (and by no means not only among astronomers), which lasted until 1931, when a new organization, the International Council of Scientific Unions replaced the IRC at the end of its mandate, and dropped from its statutes any restriction on country membership (for details, see, e.g., Cock 1983 for biology, and Blaauw 1994 for astronomy). $\dagger$

Irrespective of the somewhat gloomy climate of 1919, on the very day of its foundation, the IAU was ready to operate. To broaden the country membership, while remaining within the boundaries of the IRC statutes, National Committees (for the IAU) could be formed, under the responsibility of their main Academies or equivalent learned societies (not by governments). For the sake of effectiveness, using a top-down approach its first Executive Committee created 32 Standing Committees, broadly covering all fields of astronomy at the time (already including "Relativity"; more below), as well as organizational issues ("Astronomical Expeditions"). Two more astronomy-related international organizations were also created in Brussels, independently of the IAU: the International Time Commission and the International Bureau for Astronomical Telegrams (with their own organizational status; in parallel there were more scientific IAU Standing Committees on "Time" and on "Astronomical Telegrams").

The list of the 1919 Standing Committees, and of their first Presidents, taken from the book by Blaauw (1994), is given in Fig. 2.

Let's now examine the political background of this list, compared to the IRC (and IAU) statutes, i.e., that of the nationalities. First, the dominant countries in terms of Standing

$\dagger$ There would be of course subsequently major political hurdles: the Federal Republic of Germany eventually joined the IAU only in 1951, and the Democratic Republic of Germany from 1962 to the reunification in 1990 (see R. Wielen, this volume). Austria joined in 1955.

$\ddagger$ Four additional IRC organizations were created in Brussels at the same time as the IAU: the International Union of Geodesy and Geophysics, the International Union for Radio Science, the International Union of Pure and Applied Chemistry, and the International Union of Biological Sciences. 
The Standing Committees and their first Presidents are listed below [7]:

No. 1, Relativity (A.S. Eddington),

No. 2, Re-editing and publication of ancient works (J.L.E. Dreyer),

No. 3, Notations and Units, and the format of publications (P. Stroobant),

No. 4, Ephemerides (P.H. Cowell),

No.5, Abstracts and Bibliography (B. Baillaud),

No. 6, Astronomical Telegrams (G. Lecointe),

No. 7, Celestial Mechanics and Tables (H. Andoyer),

No. 8, Meridian Astronomy (S.S. Hough),

No. 9, Theoretical and Applied Astronomical Optics (M. Hamy),

No. 10, Solar Radiation (C.G. Abbot),

No. 11, Spectroscopic Velocities (H. Deslandres),

No. 12, Atmosphere of the Sun (G.E. Hale),

No.13, Astronomical Expeditions (A. de la Baume-Pluvinel),

No. 14, Wavelength Standards and Spectral Tables for the Sun (C.E. St.John),

No. 15, Rotation of the Sun (H.F. Newall),

No. 16, Physics of Planets (V. Cerulli),

No. 17, Lunar Nomenclature (H.H. Turner),

No. 18, Radiotelegraphic Longitude Determination (G. Ferrié),

No. 19, Latitude Variation (H. Kimura),

No. 20, Minor Planets (E.W. Brown)

No. 21, Comets (A.O. Leuschner),

No. 22, Meteorites (W.F. Denning),

No. 23, Carte du Ciel (H.H. Turner),

No. 24, Stellar Parallaxes (F. Schlesinger),

No. 25, Stellar Photometry (F.H. Seares),

No. 26, Double Stars (R.G. Aitken),

No. 27, Variable Stars (S.I. Bailey),

No. 28, Nebulae (G. Bigourdan),

No. 29, Spectral Classification (W.S. Adams),

No. 30, Stellar Radial Velocities (W.W. Campbell),

No. 31, Time (R.A. Sampson),

No. 32, Calendar Reform (G. Bigourdan).

Figure 2. "Standing Committees", as created by the first IAU Executive Committee, together with the foundation of the IAU in 1919 (from Blaauw 1994). Note No.1: "Relativity". The successful total solar eclipse expedition led by A. Eddington had taken place only two months before. (See text for details.)

Committee Presidents are by far the USA/GB/F trio: USA 11 (Abbott, Adams, Aitken, Bailey, Brown, Campbell, Hale, Leuschner, Schlesinger, Seares, St. John), Great Britain 7 (Cowell, Denning, Eddington, Hough, Newall, Turner, Sampson), France 6 (Andoyer, Baillaud, de la Baume-Pluvinel, Bigourdan, Deslandres, Hamy, Ferrié). Interestingly, among those Leuschner was of German origin, and Denning was an amateur, distinguished by the RAS. Three other Allied countries were represented: Belgium, with Lecointe and Stroobant, Italy with Cerulli, and Japan with Kimura. There was also Dreyer, born in Denmark (a neutral country which would join the IAU in 1922), but who had moved to Ireland and became a British citizen in 1885. So he should probably be counted as British astronomer, raising the census to 8. In the end, over a third of the IAU Presidents were Americans, and 25 out of 30 were from the major Allied countries. Yet, other countries were represented at the Brussels conference: Brazil, Australia, Canada, New Zealand, South Africa, Greece, Poland, Romania and Serbia. Among them, only Canada and Greece joined the IAU right away, so could conceivably have had also a Standing Committee President seat if these has been appointed purely on political balance arguments, which obviously was not the case. 


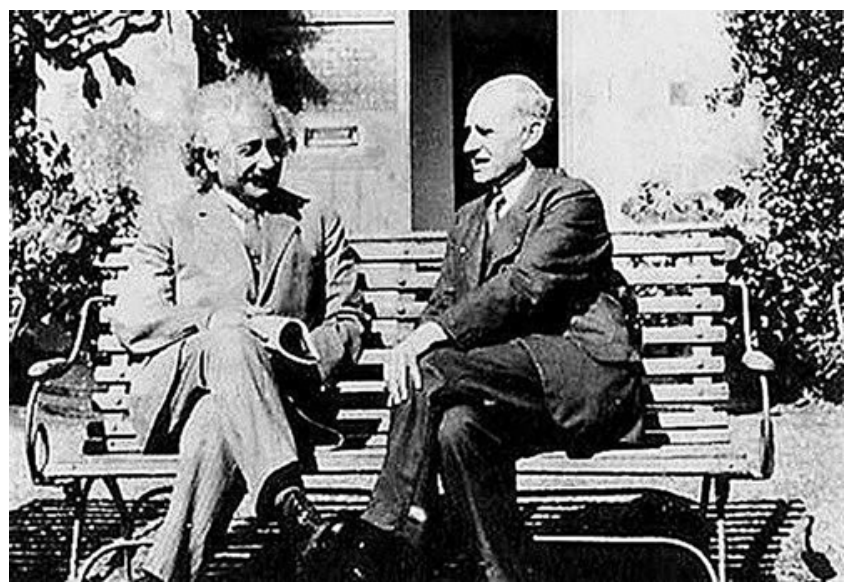

Figure 3. Two pacifists: Eddington, the British Quaker, chatting with Einstein, the German Jew (here ca.1930). Eddington was an early supporter of Einstein, in spite of the war. This attitude was not always positively appreciated by the scientific community at the time (see, e.g., Isaacson 2007). Eddington would be IAU Vice-President (1925-1928), and President (1938-1944).

Secondly, let's make a few remarks about the scientific and organizational aspects. Clearly, the list shown in Fig. 1, in its official IAU ordering as it was published in the IAU Transactions of 1922, shows no attempt at a topical classification: for instance, the three Standing Committees related to publications are numbered 2, 3 and 5; "Astronomical Expeditions" is listed between the closely related "Atmosphere of the Sun" (No. 12) and "Wavelength Standards and Spectral Tables for the Sun" (No. 14); on the other hand, "Minor Planets", "Comets", and "Meteorites" are grouped (Nos 20 to 22), etc. The idea was probably that these Committees were not necessarily permanent, so their numbering and possible interrelations would evolve with time anyway - which was indeed the case for almost a century, until the Commission reform of 2015.

Obviously, however, irrespective of their order, these Committees reflected the ideas of the Executive Committee on the state-of-the-art in astronomy and astrophysics at that time, whether traditional (like No. 8, "Meridian Astronomy", or No.17, "Lunar Nomenclature"), or more advanced observational methods (No.9, "Theoretical and Applied Astronomical Optics"; No. 18, "Radiotelegraphic Longitude Determinations"; No. 29, "Spectral Classification"), while supporting long-term projects (No.23, Carte du Ciel).

One Standing Committee, actually listed as No. 1 ("Relativity") deserves more discussion. Its President was Arthur Stanley Eddington (Fig. 3, chatting with Albert Einstein later), who had just come back from his solar eclipse expedition to the island of Principe, off the coast of present-day Gabon (Eddington 1919). The aim was to prove Einstein's General Relativity prediction, made four years earlier, of the light-ray deviation by gravitation: the very long (almost 7 minutes) eclipse took place on May 29, 1919, exactly two months before the creation of the IAU - i.e., before the creation of Standing Committee No. 1! (And, one might argue, of No. 13, "Astronomical Expeditions"... ). Alas, in spite of the success of the expedition and the validation of Einstein's theory, of which Eddington was a fervent early supporter, there was still a lot of skepticism about it, which only a handful of scientists would know about (since Einstein's papers were published in German by the Prussian Academy of Sciences; see, e.g., Einstein 1916), or could even understand at that time (see Isaacson 2007). There were also few observing activities in sight, except seeking confirmations of the Principe results, relying on rare and costly expeditions of 
land-observable, long enough, total eclipses (the next one would take place in 1937). So this Committee was disbanded in 1925, at the Cambridge (UK) General Assembly, in Eddington's home town. But Einstein's General Relativity predictions and the IAU structures would be linked again in 2006 and in 2015, a hundred years later (see below).

A different consideration is demographics, in other words the IAU membership, or its "population" of astronomers. Indeed, creating 32 Standing Committees to bring the IAU to international scientific life required manpower. This would start to happen at the 1922 General Assembly in Rome. With the adherence of Australia, Brazil, Poland, Romania and South Africa as (former) Allied countries, and of Czechoslovakia, Denmark, Mexico, the Netherlands, Norway and Spain as (former) neutral countries, in addition to the founding countries (so 19 member states in all), the IAU had admitted 207 individual members. One condition for admission was the mandatory affiliation to at least one of the 32 existing Standing Committees. So on average each Committee would have about six members only! Actually, some turned out to have up to a dozen members, but the fact is that their membership was anyhow very small - however in proportion with the very small number of astronomers world-wide (but as we saw, some of them very influential), while keeping in mind the exclusion of major countries like Germany and its allies, and also the Soviet Union (which would join the IAU in 1935). In short, as pointed out by Blaauw (1994), the Standing Committees of 1922 were actually more like Working Groups than like today's much more populous Commissions...

\section{A century of exponential growth of the IAU}

The structure of the IAU, as implemented "top-down" in Brussels, was put to the test at the first General Assembly, held three years later in Rome (2-10 May, 1922). Out of the 207 individual members, 83 attended. The 32 Standing Committees presented their reports, and it was decided to discontinue six of them, some perhaps surprisingly (Re-edition of classical works, Solar Radiation, Spectroscopic Velocities, Astronomical Expeditions, Comets and Calendar Reform). There was no formal procedure, and the small number of participants probably helped in reaching a consensus. Renamed "Standing Commissions", then simply "Commissions", these groups were to have a long life: out of the remaining 26, as many as 18 (up to No. 31, "Time", already created in 1919) would last until the 2015 reform, a lifetime of almost a century!

Another decision, more of a political nature, took place: a revision of the statutes allowing the IAU President to invite delegates to attend IAU meetings (mainly the General Assemblies) ... provided they are subjects of one of the countries entitled to adhere to the Union... In other words, even astronomers of the former Central Powers could be invited on a personal basis, in spite of the IRC restrictions on the adherence of countries. This (and other similar moves by other communities, like the biologists, see Cock 1983) paved the way to the IRC agreeing in practice to lift all restrictions on countries in 1926. After that date, the IAU could become truly international.

Returning to Commissions, their numbering was still without logic, new ones were just numbered sequentially; 55 Commissions were created and 15 terminated over the period 1922-2015, leaving 40 in all in 2015, 14 having been created after WW II. But while this could be taken as a relative structural stability of the IAU and slow change compared to political events and scientific developments, the main factor that shaped the evolution of the IAU in the XXth century was the irresistible growth of its demographics. Precisely because of this growth, contrasting with this stability, the Commissions also grew in size, and increasingly fast, bloated in some cases to comprise over 1000 members, very far indeed from the situation of 1922 . . It is in large part because of this situation, that restructuring the IAU was progressively felt necessary, if not indispensable. But the issue turned out to be far from simple arithmetical considerations. 
IAU National Members admitted
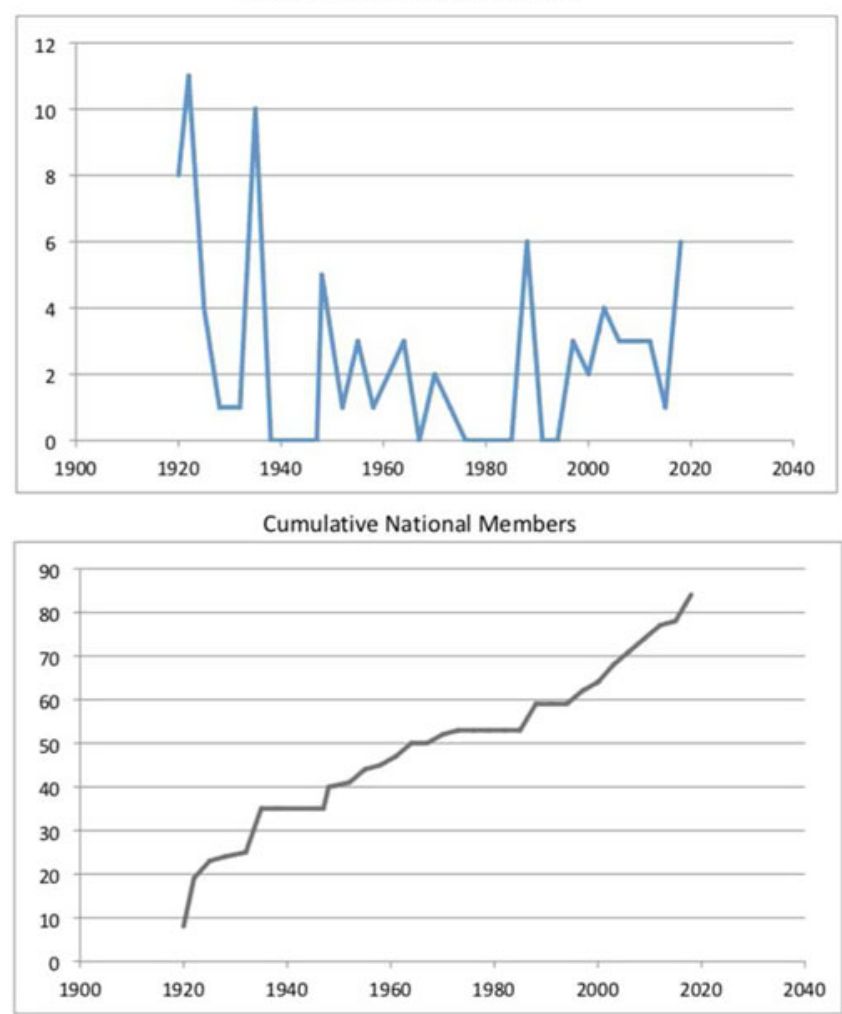

Figure 4. The growth of the IAU over a century. Top: Number of National Members (i.e., countries) admitted at each General Assembly since 1922. There was a gap of ten years (1938-1948) because of WW II. Bottom: Cumulative distribution. See text for details. (Data: IAU web site: www.iau.org/administration/membership)

Let's first examine the situation of the National Members, i.e., the IAU member countries. Extracting data from the IAU web site, I have compiled the evolution of the number of National Members admitted at each General Assembly (GA) since 1922 (with some details explained in the caption of Fig. 4a), and their cumulative distribution (Fig. 4b).

From Fig. 4a, one sees that, with two major exceptions, the number of National Members admitted at each GA is only a few, being zero on a number of occasions, and with large variations from GA to GA. The two exceptions are the first, 1922 GA, in which 11 countries were added to the eight original ones, and the 1935 GA in Paris, which saw the admission of ten new members at once (the USSR: Russia and five of its member Republics; Croatia, Estonia, Serbia; as well as China, nowadays referred to as China Nanjing - China Taipei would be admitted in 1959). When one draws the cumulative distribution (Fig. 4b), pending the GA-to-GA fluctuations, the growth is basically linear, reaching 84 countries in 2018.

But the growth of the IAU is not so much due to the number of its National Members (especially in recent years, which saw the admission of small countries with few individual members each), but to the internal growth of the number of astronomers in developed countries, which is overall more like an exponential.

Fig. 5 shows the evolution of the IAU membership, from almost a century: 1922 to 2018 (as available on the IAU web site), to which I have added a few remarkable dates: $(i)$ political, (ii) for astronomy, and ( $i i i)$ for the IAU (an admittedly somewhat biased choice...). 


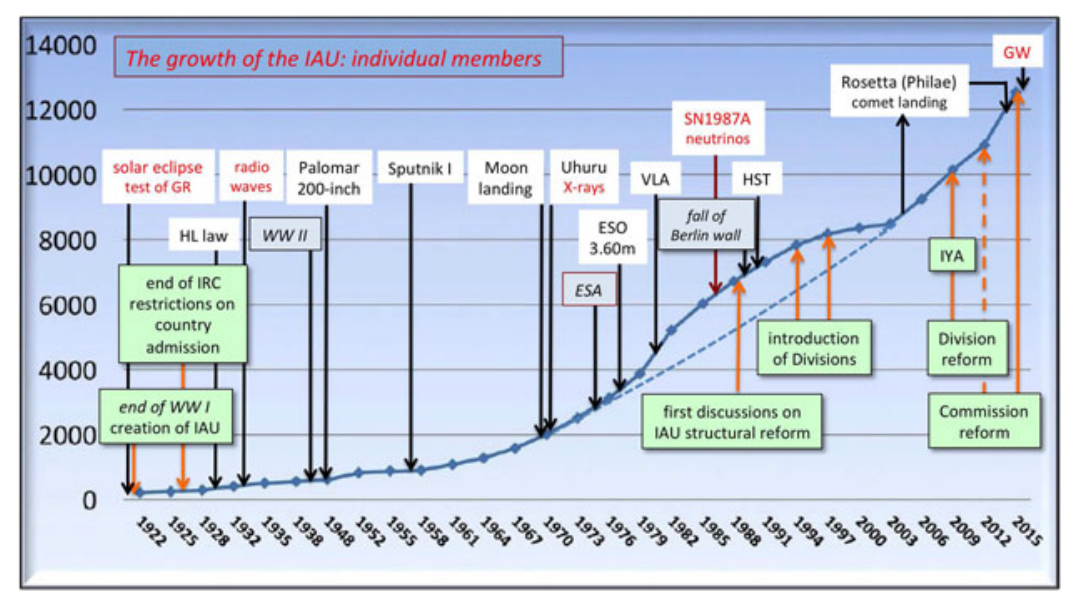

Figure 5. IAU growth: individual members (continuous curve; dots indicate General Assemblies, from www.iau.org/public/themes/member_statistics) and key dates. (The dashed curve is an exponential interpolation between 1970 and 2003.) (i) The end of WW I and the creation of the IAU (1919); the end of the IRC restrictions on country admission (1926); WW II (1939-1945); the foundation of ESA (European Space Agency, 1975); and the fall of the Berlin wall (end of the Cold War, 1989). (ii) The total solar eclipse of 1919, which allowed to confirm the deviation of light by gravitation (Einstein's General Theory of Relativity, 1915); the Hubble-Lemaitre Law (HL; 1929); the discovery of cosmic radio waves by K. Jansky (1932); the commissioning of the Palomar 200-inch Hale telescope (1947), the largest in the world until the Zelenchuk 6-m telescope became operational in 1974; the launch of Sputnik 1 on Oct.4, 1957, the first artificial satellite; the Apollo 11 first Moon landing on July 20, 1969, 50 years after the creation of the IAU; the launch of Uhuru in 1970, the first of the Small Astronomical Satellite series, which opened a new window on the Universe by surveying the sky in X-rays; the ESO 3.6-m telescope, commissioned in 1977, which was Europe's gateway to large telescopes; the Very Large Array, the world's largest radio telescope and interferometer, operational since 1980; the discovery of the SN1987A supernova, allowing the first detection of neutrinos from an extrasolar source; the Hubble Space Telescope, launched in 1990, the first of a new generation of astronomical telescopes in space; ESA's Rosetta mission to comet $67 \mathrm{P} /$ Churyumov-Gerasimenko, launched in 2004, and the landing of its Philae module (2014); and the discovery of gravitational waves $(\mathrm{GW})$ in 2015. (iii) The other labels refer to the successive steps leading to the IAU structure we know today. Details are explained in the text. IYA: International Year of Astronomy, 2009.

These dates are explained in the figure caption (they are also labeled in a self-explanatory way); those referring to the IAU are discussed below.

Secondly, let's indeed have a closer look at the population curve. It appears to be basically an exponential, with an excess "bump" lasting over 20 years, starting around 1970 until 2003, over a simple "background" population $N(t)$ having an $e$-folding time $\tau \sim 24.4$ yr [more precisely: $N(t) \sim 2000 \exp (t-1970) / \tau$; dashed curve on Fig. 5] between these dates. After a continuous, but slow growth up to the sixties, which appears (at this scale) essentially linear and unaffected by political considerations, like the IRC or even WW II, or by major astronomical discoveries or facilities (Hubble-Lemaître law, 1929, Palomar 200-inch, 1947, etc.), the number of IAU members starts to pick up. A good reference date is the start of the space age, with the launch of Sputnik 1, the first artificial satellite, in 1957. This date (or equivalently that of the 1958 GA in Moscow that followed) also approximately corresponds to the 1000-member mark for the IAU - a 5-fold increase in 40 years.

The 2000-member mark was then reached much faster. In 1970 (Brighton GA), the IAU membership had doubled in a decade only! Another decade would elapse, and the IAU 
membership would double again, to reach about 4000 in 1979 (Montreal GA). Six years later, at the 1985 GA in New Delhi, at the height of what we see now as the bump, the IAU gained another 2000 members, reaching 6000.

It is certainly beyond the scope of the present paper to analyse in detail the reasons for the start of this spectacular extra growth (one would have to examine the data for each country), but the access to space likely played a key role in the bump, with the Moon landings in the 1970s, the new windows on the universe starting with the Uhuru X-ray satellite, the creation of ESA in 1975, etc. All these developments benefited from Cold War military efforts not only in launcher and satellite technologies, but also in new detectors, mainly CCDst, opening the way to, e.g., IR observations from space with IRAS in 1983. Interestingly, the bump reached a maximum at the time of the fall of the Berlin wall (1989), i.e., marking the end of the Cold War, and then decreased, probably due, at least in part, to the subsequent deceleration of space research.

An indication is that the growth of the IAU in the sixties apparently did not suffer too much from the economic problems resulting from the oil crisis of 1973, and that it was not caused either by a massive influx of astronomers from new countries. Since 1959 and to the present day, the only countries with the largest number of admitted members were China Taipei (1959), India (1964) and the Republic of Korea (1973): these countries now total 588 members, but at the start of the bump (ca. 1980), assuming a growth proportional to the IAU population, thus about one third of what it is now, we find an addition of about 200 members only over that period of time. At its maximum, from Fig. 5, the bump represented an excess of approximately 1000 astronomers over the background population: it is thus not unreasonable to suggest that the majority of these were astronomers involved in space research.

The bump ended in 2003 (Sydney GA), but the background population of astronomers continued to grow fast. The 10000 members mark was reached in 2009 (Rio de Janeiro GA), and another 2500 were admitted in the following six years (2015 Honolulu GA). The latest census (2018 Vienna GA) amounts to 13500 individual IAU members - nearly 70 times their number a century ago. Interestingly, in spite of an apparently linear behaviour during the early years, the growth of the IAU has actually been exponential all along, with essentially the same $e$-folding time of $24.4 \mathrm{yr}$. (So extrapolating to the next 20 years, by 2040 the IAU would have some 35000 members!)

What to do, then, with an IAU structure entirely built over 30-40 Commissions? The numbers speak for themselves: on average, this would mean today an average of 400-500 members each - far from the small groups that formed the IAU in the 'twenties, or even from the classroom-sized Commissions of the 'seventies. This question was at the heart of the successive reforms that started to be discussed near the peak of the bump, when the IAU membership had already reached nearly 7000 astronomers - then coming from 59 countries.

\section{The long road to Divisions (1989-1994)}

As is well known, the concept of Divisions was first implemented by Lo Woltjer during his term as IAU President (1994-1997). But it is worthwhile tracing back the long maturing process by which they came to be formally approved at the 1997 GA in Tokyo.

The most direct, hands-on way to do this is to consult the Minutes of the past Executive Committee (EC) meetings, made readily available on the IAU web site: usually there is a Section on "Commission Matters", which allows a quick search. These Minutes are numbered sequentially; I shall refer to them as "ECn", where " $n$ " is the numbering sequence. The EC holds one meeting each year, taking place at the invitation one of

$\dagger$ First flown in space aboard the US military surveillance satellite KH-11 in 1976. 
its members, generally in April-May, except during GA years, where, in addition to that meeting, the EC meets two or three times during the GA to report to the General Assembly, present Resolutions, and more generally follow the conduct of the GA in real time. While this is generally a smooth process, it can be hectic, as was the case for the famous 2006 GA in Prague, with the Resolutions on Pluto (see, e.g., T. Montmerle, and R. Ekers, this volume).

The first EC meeting (EC1) took place at the same time the IAU was created (July 28, 1919), while the 100th meeting (EC100) took place in Vienna in April 2018, in preparation for the GA. The IAU Transactions, issued every three years, are also the place where the decisions taken during the GAs are published, while publication in the IAU Information Bulletin (numbered "IBn"), issued twice a year, was meant to provide a faster dissemination of news and important EC decisions. (These news are now posted almost in real time on the IAU web site, and circulated within the community via the IAU e-Newsletter since 2006.)

The first mention of a possible restructuring of the Commissions appears to be found in the Minutes of EC59 (Stockholm, Sep.1-4, 1989: IAU President Y. Kozai, General Secretary D. McNally), following the 1988 GA in Baltimore. The Minutes report 6711 individual members. The Section on "Commission Matters" mentions that Commission 10 (Solar Activity) and 12 (Solar Radiation) considered a merger and were polling their members; the EC itself would welcome such a merger. (Eventually this merger did not take place, because, according to the Minutes of EC61, Commission 35, Stellar Structure, objected, but agreed that Commission 12 would be renamed "Solar Radiation \& Structure", to be approved at the following GA; more below.) Also, a question was put to the EC

regarding the mechanism for forming a new Commission of the Union. This request indicated that no formal mechanism was clearly laid down in either Statutes, Bye-laws or Working Rules apart from the fact that new Commissions were established by the General Assembly. The General Secretary had informed Prof. Vicente that a strong scientific case supported by a significant number of Commissions would be the minimum requirement needed by the Executive Committee before any recommendation could be made to the General Assembly. It was agreed to leave matters at that point and await a proposal. $\dagger$

The underlying suggestion was thus that the Commissions would have to mutually agree on their restructuring - an admittedly democratic, but perhaps not the most efficient, way to promote change.

Then a sentence is found in the Minutes of the following EC (EC60 in Munich, 1990):

A paper on the reform of the Commissions structure of the Union, presented by the General Secretary at Executive Committee 59, was not pressed in view of the clear opposition of the Commissions to merger at this time and other objections by the Executive Committee.

So the General Secretary had apparently decided to go ahead, and follow up on the suggestion of merging Commissions by circulating a proposal to the EC. Unfortunately, such an interesting document about the "reform of the Commissions" is neither mentioned in the Minutes of EC59, nor appended to the Minutes of EC60 (although it could conceivably be dug out from the IAU Archive boxes). But this indicates that the issue had been officially raised, and first efforts at solving it attempted.

The following year saw the organization of the 1991 GA in Buenos Aires (July 23Aug.1). Two EC meetings were held during the GA, EC61 and EC62, chaired by

$\dagger$ Italics are used when quoting verbatim the original documents. 
the incoming President, A.A. Boyarchuk, flanked by L. Woltjer as President-Elect, J. Bergeron as General Secretary, and I. Appenzeller as Assistant General Secretary. The issue of "restructuration of Commissions" was not left behind, but brought again to the agenda. The Minutes of EC62 mention:

Commissions: merging or new system.

The EC meeting coming to its end, there was not much time to discuss in depth the important issue of merging commissions or of a possible new system. During the last triennium, 1988-1991, the suggestions of merging made by the General Secretary, D. McNally, to several commissions did not meet the approval of the commission Presidents/Organizing Committees. This important point of the future of the IAU Commissions will be on the Agenda of the 63rd meting of the EC.

Then came EC63, which met in Bangalore in 1992 (Aug.11-15). The Minutes do mention the Restructuring of Commissions:

The proposal written by the General Secretary [J. Bergeron] is discussed. The $G S$ is requested to prepare a new proposal, taking into account remarks concerning the reduced number of commissions envisaged, and the role devoted to the working groups. In order to initiate a wide discussion among the IAU members, the new proposal will be sent to IAU commission Presidents $\&$ vice-Presidents and will be summarized in the Information Bulletin (see Annexe 1).

Indeed, the revised proposal was published a few months later in IB69 (Jan. 1993); the text is reproduced in full in Appendix A. I quote here the key points.

In the introductory paragraph:

Broad scientific themes would imply commissions of a size similar to that of the largest commissions of the Union ( 700 members). Specific tasks and services would then be conducted within smaller entities (Working Groups) whose life span would be limited to the time needed to work out these targets.

The new structure would then be a "compression" of the existing one, with larger Commissions (merged or reorganized), and larger Working Groups, of limited lifetime to allow for a turnover of topics. This is somewhat expanded in $\S 1$ :

There would be larger Commissions with broad scientific themes that reflect the current fields of astronomy. About a dozen of such large Commissions are envisaged. The objectives of the new Commissions should be redefined in the light of the new tasks of the Working Groups... On this matter, an input is expected from the current Commission Presidents and vice-Presidents.

In other words, the EC was relying mainly on the Commissions to restructure themselves.

As to the Working Groups, where definite tasks would be accomplished, $§ 3$ reads:

The life span of WGs would be more limited than that of Commissions to ensure a real turnover of their activities. These activities would be reviewed at each GA and the WGs would be reconducted for another triennium only if the need of pursuing their current project or to start new activities has been argumented, and if the tasks assigned for the past triennium are well under way.

Then $\S 3$ continues with a specific emphasis on mergers:

A step towards the new structure could be adopted at the XXIIIrd GA: merging between current Commissions. Although the suggestion of Commission merging 
made during the previous triennium by the General Secretary [D. McNally] did not meet the approval of Commission Presidents/Organizing committees, the concept of mergers is part of a restructuration scheme.

A few suggestions of mergers follow (see Appendix A).

This proposal apparently was not received more favorably than the previous one, because a year later, the IB72 (Jan. 1994) reports that a second draft of the proposal was sent to Commission Presidents and Vice-Presidents on Sep. 13, 1993. This was just a few weeks after the Executive Committee had met in Shanghai (EC64, June 25-28, 1993), and analysed the replies from the Commissions.

This time, the Minutes include a fairly extensive account of the discussion that took place between EC members at EC64. Of the text (which is reproduced in full in Appendix B), I extract a few revealing sentences:

... Those who were against would have responded more favorably would the proposal have been written differently, i.e. indicating the aims of the IAU. It seems that they are not against the reform, but that they would have preferred to decide by themselves. They will discuss between themselves and come with a proposal of reorganization.

L. Woltjer [President-Elect] has analysed the replies as follows: 1) several presidents and others ask what is unsatisfactory, 2) any idea of an intermediate stage is dangerous and 3) there is a very broad concern on how large commissions will function. Answers of presidents have been very different and, that it is difficult to classify those who are pro or $\operatorname{con}(. .$.$) .$

He [L. Woltjer] also stresses that the Executive Committee has to be cautious not to give the feeling that it wants to impose something and that the decision should go to the commissions. It would be catastrophic if such a move eliminates the most prominent members and share the concern about the functioning of large commissions.

Once again, the problem of very large Commissions is evoked: M. Roberts [VicePresident] wonders what a commission of 1000 persons would mean?

And A. Boyarchuk, the IAU President, concludes:

[I have] the feeling that our society is not ready to go through a radical change and [I am myself] strongly against to see commissions disappear. [I think] that the problem is how to solve this problem: inputs should be received before the General Assembly, in order to do all the work during the General Assembly. The document exists, and has to be discussed. Time for business sessions has been restricted, although members may want to discuss this at length. Consequently, [I consider] that the necessary time has not been given, as it is more a General Assembly business matter than an Executive Meeting one.

Obviously, the Commissions' answers to the Restructuring document were disturbing, even questioning the motivations behind it, and quite clearly opposing mergers (see the above example of Commissions 10, 12 and 35, all Solar Commissions). Also, the issue of the inevitably large size of merged Commissions was immediately raised. Finally, there was a "legal" issue, as to which body would be entitled to pursue the initiative, the EC or the General Assembly (with typically 2000 participants at that time)?

Nonetheless, a seed had been planted: M. Roberts (Vice-President) noted:

that the proposal as it stands is proposing 10 sections (750 members each) and

25 working groups, i.e. a double structure, which should ensure a good flexibility.

The key words are here: double structure.

The following year, 1994, was the year of the GA in The Hague, the capital of the President-Elect Lo Woltjer's homeland, which took place on Aug. 15-27. The idea of a 
Scientific Divisions

1. Fundamental Astronomy

2. Sun, Heliosphere

3. Solar System

4. Stars

5. Variable Stars

6. InterstellarMatter

7. GalacticSystem

8. Galaxies and the Universe

9. General

Technique oriented Divisions

10. Optical

11. Radio

Mixed Divisions

12. Space/HighEnergy

\section{Commissions}

$4,7,19,31$

$10,12,49$

$15,16,20,21,22$

$26,29,35,36,45$

27,42

34

33,37

28,47

$41,46,51$

$8,9,24,25,30$

40

$44 / 48$
Members

424

763

667

964

619

657

512

915

500

752

645

\section{Commissions $5,6,14,38$ and 50 do not easily fit into such a framework and might be directly} attached to the EC, or included in division 9.

Figure 6. IAU's first divisional structure, as proposed by L. Woltjer on Aug.13, 1994, i.e., just one day before the first EC meeting of the General Assembly in The Hague. Note that many Commissions do not fit the overall scheme, in spite of the introduction of a Division entitled "General".

double structure matured. Since merging (or "amalgamating") Commissions obviously faced resistance, the idea of "sections" with "working groups" evolved, albeit the other way around: to leave the Commissions (and their Working Groups) intact, but form groups of a few Commissions, to be overseen by new super-structures: the Divisions, while keeping a reasonable demographic balance between them.

On Aug. 13, 1994, from Geneva, L. Woltjer circulated a three-page document to the EC entitled: "Restructuration of IAU Commissions: An alternative" (meaning: "to the existing proposal", i.e., the one for which there had been no consensus among Commission Presidents even after another revision). The text is given in full in Appendix C, but again I quote here key paragraphs:

Whatever views one may have about the merits of specific proposals, it seems difficult to simply do nothing. It has been frequently mentioned that the younger members seem disaffected with the IAU. While a certain lack of interest in commission matters on their part may be rather natural, nevertheless the general perception of the IAU as being an organization mainly preoccupied with "old fashioned" scientific topics, in which the practitioners of the newer subjects have only limited influence, is worrisome. And such opinions prevail not only among the young. In addition, rightly or wrongly, many of the commissions are perceived to be little closed "clubs" that have not much interest in letting new winds blow through. Finally, the discussions of the last three years have raised expectations among those favoring change, and doing nothing will lead to a strong sense of deception.

At the same time it is clear that the Executive Committee cannot and should not try to force extreme changes on the commissions against their will. A solution has to be found which preserves the positive of the present situation, while satisfying those who want renewal.

Then L. Woltjer goes on to propose a "set of Divisions", gathering Commissions into groups (shown in the Table of Fig. 6), and yielding an acceptable demographic balance between those Divisions, with most of them in the 600-800 member range, and extremes 


$\begin{array}{ll}4.8,19.24,31 & 454 \\ 10,12,49 & 763 \\ 15.16,20,21,22 & 667 \\ 26,29,35,36,45 & 964 \\ 27,42 & 619 \\ 34 & 657 \\ 33,37 & 512 \\ 28,47 & 915 \\ 9,25,30 & 531 \\ 40 & 752 \\ 44 / 48 & 645\end{array}$

Commission 14 would become a commission of the EC. For the moment Commissions 7, 41 and 51 would remain unattached to a division."

Figure 7. Revised divisional structure adopted at The Hague GA. Some names would evolve later: "Solar System" became "Planetary Systems Science" (after the discovery of exoplanets orbiting solar-type stars in 1995); "Optical Techniques" became "Optical and Infrared Techniques".

of about 500 and about 900 members. Also, by calling attention to the younger generation and a certain will for change, instead of the purely organizational problems discussed since 1989 , L. Woltjer introduced a scientific vision of the future of the IAU.

The first of the EC meetings at The Hague GA (EC65) was spread over four sessions (Aug. 14, 15, 16 and 22). L. Woltjer's proposal was approved by the EC and circulated among Commission Presidents and Vice-Presidents for a feedback to the EC Officers $\dagger$ on Aug. 22. It was well received this time, then slightly amended and rearranged (11 Divisions instead of 12). The final text can be found in Appendix D. The emerging Divisional structure is given in Fig. 7.

The second EC meeting at the GA (EC66) took place on Aug. 25, with a new EC comprising L. Woltjer as incoming President, and I. Appenzeller (Germany) as incoming General Secretary; the other members were: R. Kraft (USA), President-Elect, J. Andersen (Denmark), Assistant General Secretary, and, as Vice-Presidents, C. Anguita (Chile), B. Hidayat (Indonesia), D.S. Mathewson (Australia), F. Pacini (Italy), J. Smak (Poland) and V. Trimble (USA). The new Divisional structure had been approved by a simple vote of the General Assembly. The Section "Commissions and Working Groups" of the Minutes soberly says:

Restructuring of Commissions and Working Groups

The EC takes note of the approval of the Division structure by the Commission Presidents and the General Assembly and instructs the General Secretary to follow up on these decisions.

A proposal to modify the statutes correspondingly will be discussed at the next EC in order to be submitted to the adhering organizations one year prior the XXIIIrd General Assembly.

It is suggested that Divisions could be allotted 1/2 to 1 page of each Information Bulletin to spread information to members concerning the activity of the Division.

The EC also feels that the layout of the Bulletin should be made more attractive.

In retrospect, after two triennia of slow evolution, hindered by the apparently intractable problem of how to merge Commissions, the approval process pressed by L. Woltjer went extremely fast. Contrary to the previous Commission/Working Group proposal allowing for a long reflection period, the proposal introducing Divisions was not circulated beforehand to the community (no Information Bulletin news), but presented after EC approval to the Commission Presidents and Vice-Presidents at the GA

$\dagger$ IAU President, President-Elect, General Secretary, and Assistant General Secretary 
itself. The new structure was not put to the GA vote by way of a Resolution - which normally have to be submitted six months in advance and circulated among GA participants. Obviously, L. Woltjer had realized that the Commission merger approach would never be successful, and with his blitzkrieg strategy, the new structuring proposal was approved by the GA in less than two weeks, albeit to be followed by a triennium to test its viability within the whole community.

Once the GA was over, the Divisions started to organize themselves based on their "daughter" commissions, elected their Presidents and Organizing Committees (following the same procedures as Commissions) in the following months, under the supervision of the EC. At the following Kyoto GA in 1997, the Report presented by the Executive Committee simply mentions:

The 11 Divisions introduced on a trial basis at the XXIInd General Assembly fulfilled their mission very satisfactorily, leading to their adoption on a permanent basis through the revision of the Statutes, Bye-Laws and Working Rules approved al the XXIIIrd General Assembly. In particular, the advice of the Division Presidents was solicited and carefully considered by the Executive Committee in the selection of IAU sponsored scientific meetings. Considerations were also initiated regarding the optimum organisational structure within each Division. During the triennium, Commission 7 joined Division I and Commission 50 joined Division III.

The creation of a Divisional structure for the IAU thus became formally effective nine years after the first discussions took place. Divisions were ordered using Roman numerals, and a twelfth Division (Div. XII) would be added in 2003. Entitled "Union-Wide Activities", it essentially gathered the "orphan" Commissions of 1994, that were previously under the purview of the EC: 5 (Documentation \& Astronomical Data), 6 (Astronomical Telegrams), 14 (Atomic \& Molecular Data) on the one hand, and 41 (History of Astronomy), 46 (Astronomy Education) and Commission 55 (Communicating Astronomy with the Public; created in 2006, the year of the start of the "Pluto Affair"), on the other.

However, beyond the step of the creation of the Divisions, perhaps the most important feature of the restructuring was that the new Division Presidents and Vice-Presidents took over the role of consultants to the EC, albeit on fairly "neutral" issues like participating in the selection of IAU meetings, that the Commission Presidents and Vice-Presidents had held until then, on the condition that they would interact with their respective Commissions of course. This looked very much like a revised version of the "double structure" that M. Roberts had mentioned in the discussion reported in the Minutes of EC64 of 1993 (see above), and which had been, in a way, initiated by my predecessor Derek McNally six years earlier. In practice, the double structure had de facto evolved into a "triple structure", or more precisely into a lasting, "three-tier", hierarchical structure: Divisions/Commissions/Working Groups.

\section{Reforming the Divisions (2009-2012): why and how}

All being considered, the new structure was not a revolution, but a reform emanating from the EC as a "top-down" project which had become acceptable to the community. As such, it didn't shake much the existing components of the IAU, Commissions and Working Groups. It was a "hybrid" reform, part administrative, part scientific. The administrative part was the three-tier structure and its respective Organizing Committees, the scientific part was the labeling of the "boxes" where the Commissions were grouped together. In addition, as mentioned previously, the numbering of the Standing Committees of 1919, then of the Commissions, was to a large extent arbitrary, so while the introduction of the Division did bring some scientific order to them, their numbering remained untouched, 
and it was thus impossible to understand in a straightforward way why this Commission belonged to that Division.

In addition, even after all the Commissions were assigned to Divisions after the creation of Div. XII, there were some oddities that had struck me even before I became Assistant General Secretary (AGS) in 2009, for instance having two separate Divisions for stellar studies: "Stars" (Div. IV), and "Variable Stars" (Div. V). An obvious reason was to keep a number balance between the Divisions, but it seemed to me that the separation criterion was not scientifically appropriate: after all, at some level all stars are variable - this is even a way to probe their internal structure (asteroseismology). Another oddity was Div. XII itself, which under the name "Union-Wide activities", covered in reality activities that simply could not find find their place in other Divisions, but could however be broadly broken down into "astronomical data" issues (Documentation \& Astronomical Data, Astronomical Telegrams, Atomic \& Molecular Data) and "social" or "cultural" issues (history of astronomy, astronomy education, protection of observatory sites, relations between the astronomy with the public), two very different areas of IAU activities.

But a closer analysis after I started my term revealed more than seemingly superficial problems: for instance, Commission 26 in Div. IV included "Double stars", while Commission 42 in Div. V dealt with "Close binary stars". Three Divisions (VI, Interstellar Matter; X, Radioastronomy; XI, Space \& High-Energy Astrophysics), so many years after their creation, still had only one Commission by the same name - i.e., a clone having the same membership but a distinct Organizing Committee (OC) to cover exactly the same area - , which could be interpreted as absence of activity or disinterest for the IAU (or both). (I had this feeling while being myself a member of the Div. XI OC.)

Perhaps more seriously (or maybe that was the real reason for these issues), it seemed that the Divisional structure approved twelve years earlier had become to a large extent out of line with the fast development of astronomy: the administrative benefit, while preserving internal peace among IAU members, had somehow smothered the scientific spirit. So, with a good dose of unawareness of the task ahead, I walked in the steps of D. McNally and embarked on proposing to the EC, to consider a reform of the Divisions introduced by L. Woltjer fifteen years earlier.

Prior to my first EC meeting as AGS (EC88 in Baltimore, 11-13 May 2010), I circulated a preparatory document sketching my approach and making first suggestions, hoping to trigger discussions among the EC members: the President (R. Williams, USA), the President-Elect (N. Kaifu, Japan), the General Secretary (I. Corbett, UK); and the VicePresidents (M. Colless, Australia; M. Haynes, USA; G. Miley, the Netherlands; J. Palouš, Czech Republic; M. Rovira (Argentina) and G. Setti (Italy).

My approach was built, like Woltjer's, on the existing Commissions, but focused on science as a priority; concerns such as number balance and other administrative considerations were secondary, at least at that preliminary stage. The key tool I used as a guideline was the astro-ph literature classification, the idea being, on the one hand, that a "modernized" scientific approach to the role of the Divisions could be more or less based on this classification, and on the other hand, that more general, transverse activities were of interest to all IAU members, irrespective of their science area (an idea also implicitly present in the previous scheme).

As a result, and just for the record, the initial proposal started from the existing twelve Divisions, as follows:

- Four "Union-wide" Divisions:

- Fundamental astronomy (as is);

- Union-wide activities (as is; perhaps a better name should be found, like "Education, Outreach and Culture" - much like UNESCO); 
- "Instrumentation", or "Instrumental Research", with no distinction on wavelength;

- "Methods in Astronomy": mathematical, numerical, statistical, etc.

- Eight "Topical" Divisions:

- Sun \& Heliosphere (unchanged)

- Solar-like stars (including "the Sun as a star")

- Massive stars

- Planetary systems (unchanged)

- Interstellar matter in galaxies (extending the existing Division)

- Galaxies (could also include "galaxy formation")

- Cosmology and astroparticle physics

- High-energy astrophysical phenomena

This first proposal was well-received by the EC, and R. Williams suggested to set up a small "Executive Committee Task Group" (himself, with Ian Corbett, Martha Haynes and Giancarlo Setti, and myself as coordinator). Its membership was later extended to four Division Presidents (Chris Corbally, Russ Taylor, Christine Jones, and Françoise Genova; more below).

The Task Group started internal and external discussions, with the idea to produce a new document, this time for circulation among Division Presidents (DPs) to obtain their feedback in time for the following EC meeting (EC89 in Prague, 24-26 May 2011). For the first time in IAU history, the EC invited the DPs to attend that meeting (i.e., outside of the General Assembly), for two special discussion sessions: one between themselves separately, and the other with the EC via a spokesperson designated by them.

The draft document was circulated on 14 Feb. 2011. It included an historical background (the creation of Divisions) and motivations for change (scientific, structural and also demographic); guidelines used to propose a new structure; and guidelines and timeline for a wide consultation of the community.

As a result of the various consultations and discussions, the Task Group arrived at a streamlined set of nine Divisions, with a new numbering system (using letters to avoid confusion with the old system, but omitting "I" which could be mistaken for the Roman numeral "1"), new names and redistributed Commissions, and possibly including in the future recent/new topics in astronomy, as follows:

- "Cross-community" Divisions

- Division A Fundamental Astronomy

Commission 4 Ephemerides

Commission 7 Celestial Mechanics \& Dynamical Astronomy

Commission 8 Astrometry

Commission 19 Rotation of the Earth

Commission 31 Time

Commission 52 Relativity in Fundamental Astronomy

- Division B New Technologies, Facilities, Data

Commission 5 Documentation \& Astronomical Data

Commission 6 Astronomical Telegrams

Commission 14 Atomic \& Molecular Data

Commission 25 Stellar Photometry \& Polarimetry

Commission 40 Radio Astronomy

Commission 54 Optical \& Infrared Interferometry 
(This Division would also include new topics such as: Computational astrophysics; Large surveys and databases; Astrostatistics; High-energy instrumentation; Astroparticle detectors.)

- Division C Education, Heritage, Outreach

Commission 41 History of Astronomy

Commission 46 Astronomy Education \& Development

Commission 50 Protection of Existing \& Potential Observatory Sites

Commission 55 Communicating Astronomy with the Public

(This Division could also include two existing Working Groups: Historic Radio Astronomy, and Communicating Heliophysics.)

○ Division D High Energy \& Astroparticle physics

Commission 44 Space \& High Energy Astrophysics

(This Division would include astroparticle topics at the boundary with fundamental physics, such as non-electromagnetic "messengers" (cosmic rays, neutrinos, gravitational waves, etc.), the nature of dark matter and dark energy, etc.)

- "Topical" Divisions

- Division E Sun \& Heliosphere

Commission 10 Solar Activity

Commission 12 Solar Radiation \& Structure

Commission 49 Interplanetary Plasma \& Heliosphere

- Division F Planetary Systems \& Origin of Life

Commission 15 Physical Study of Comets \& Minor Planets

Commission 16 Physical Study of Planets \& Satellites

Commission 20 Positions \& Motions of Minor Planets, Comets \& Satellites

Commission 22 Meteors, Meteorites \& Interplanetary Dust

Commission 51 Bio-Astronomy

Commission 53 Extrasolar Planets

("Origin of Life" is suggested here as a common denominator for "Bioastronomy", "Astrobiology", "Exobiology", etc.)

- Division G Stellar Structure \& Evolution

Commission 26 Double \& Multiple Stars

Commission 27 Variable Stars

Commission 29 Stellar Spectra

Commission 30 Radial Velocities

Commission 35 Stellar Constitution

Commission 36 Theory of Stellar Atmospheres

Commission 42 Close Binary Stars

Commission 45 Stellar Classification

- Division H Interstellar Matter \& Local Universe

Commission 33 Structure \& Dynamics of the Galactic System

Commission 34 Interstellar Matter

Commission 37 Star Clusters \& Associations

(This Division would include, for instance, "ecosystems" [structure, stellar populations, etc.] of resolved, nearby galaxies, e.g., the Local Group, nearby starbursts, etc., compared with our Galaxy.) 


\section{- Division J Distant Universe \& Cosmology Commission 21 Galactic and Extragalactic Background Radiation Commission 28 Galaxies Commission 47 Cosmology}

Presented in this way, the aim of the new structure was to give more visibility and clarification to the "big picture", or the "backbone", of the IAU activities, not only for the benefit of its members, but also of the outside world, viewed as an increasingly important area of the IAU activities, especially in the aftermath of the 2006 "Pluto Affair" and the 2009 International Year of Astronomy.

To this effect, one of the main innovations was the creation of a new Division (Division C) explicitly dedicated to the IAU "societal" role in astronomy (education, outreach, history; later heritage), in particular giving more visibility to the activities of Commission 46 (one of the former Commissions directly under the purview of the EC, created in 1964), and of other post-WW II Commissions in this area (41: 1948; 50: 1973; and 55: 2006).

As far as the issue of Division membership was concerned, adding the membership of their respective Commissions (as of 2011), the numbers were the following: Div. A: 979; Div. B: 1820; Div. C: 919; Div. D: 1027; Div. E: 1194; Div. F: 1529; Div. G: 2585; Div. H: 1745; Div. J: 2088. Even though these numbers were inevitably large, in relative numbers the "reasonable balance" between Divisions turned out to be significantly better than that of the original Divisions (a maximum/minimum ratio of 2.8 compared to 3.8).

The moment of truth came in Prague (EC89). The twelve Division Presidents (in the order of Divisions: Dennis McCarthy, USA; Valentín Pillet, Spain; Karen Meech, USA; Chris Corbally [spokesperson], Vatican City State; Gerald Handler, Poland [representing Steve Kawaler, USA]; You-Hua Chu, USA; Despina Hatzidimitriou, Greece; Elaine Sadler, Australia; Andreas Quirrenbach, Germany; Russ Taylor, Canada; Noah Brosch, Israel [representing Christine Jones, USA], and Françoise Genova, France) approved the outline of the proposal, and gave the EC a "clear mandate" to proceed with the reform, subject to a future clarification of the implications of the reform for Commissions and Working Groups.

So the green light given by the Division Presidents paved the way to the adoption of the new structure at the following GA, due to take place in Beijing in 2012. Consultations between the Task Group and the Division Presidents continued. In particular, Division Presidents were invited again to EC meetings. Some cosmetic changes were made to the Divisions (in particular about their final names, some of them hotly debated at times), but it became increasingly evident that such a structural reform, based on a novel opening of the IAU towards "science and society" (for short), would miss its target if the Commissions were left untouched. After all, as mentioned previously, out of 40 Commissions in 2012, 26 had been created in 1922, i.e., almost a century earlier, and six more prior to WW II, so it was not unreasonable to reexamine their status with an open mind.

It was then decided, jointly by the EC and the Division Presidents, to pursue the effort, and, after having reformed the Divisions, to conduct a deep reform of the Commissions during the following triennium, and consequently, of their Working Groups, taking advantage of the experience already gained since 1997 in the mutual relationships between Divisions and Commissions.

That is why the EC, seeking approval of the community in Beijing, chose to put a Resolution (B4) to the vote at the GA, not only mentioning the new Divisional structure, but also explicitly giving a mandate both to the new Divisions and the EC, to propose 


\title{
RESOLUTION B4
}

\section{on the restructuring of the IAU Divisions}

\section{Proposed by the IAU Executive Committee}

The XXVIII General Assembly of the International Astronomical Union,

noting

(a) that both the IAU and astronomy as a whole have evolved considerably since the current Divisions were introduced in 1994 and formally adopted in 1997, and that it is therefore appropriate to consider re-optimising the Divisional Structure,

(b) the report and recommendations of the Task Group established by the Executive Committee to examine the case for restructuring the Divisions, and the Executive Committee response to these recommendations,

(c) that the Commissions, Working Groups and other bodies under the Divisions may also require reform,

(d) that the implementation of the Strategic Plan through the Office of Astronomy for Development $(\mathrm{OAD})$ and other associated programmes requires the Executive Committee to establish appropriate oversight and governance provisions for all Astronomy for Development activities, including the Office of Astronomy for Development, ensuring a strong link between these activities, the Divisions, and the Executive Committee.

\section{approves}

the proposal of the Executive Committee to restructure the Divisions as follows:

\author{
Division A Space and Time Reference Systems \\ Division B Facilities, Technologies, \& Data Science \\ Division C Education, Outreach, \& Heritage \\ Division D High Energies \& Fundamental Physics \\ Division E Sun \& Heliosphere \\ Division F Planetary Systems \& Bioastronomy \\ Division G Stars \& Stellar Physics \\ Division H Interstellar Matter \& Local Universe \\ Division J Galaxies \& Cosmology
}

\section{and requests}

the new Divisions, guided by the Executive Committee, to work together to produce initial plans for a revised structure for Commissions, Working Groups and other bodies to be approved, in accordance with the Statutes and Bye-Laws of the Union, by the Executive Committee at its meeting in May 2013.

Figure 8. Divisional structure adopted at the Beijing GA, after the vote of Resolution B4, on 30 Aug. 2012. The Divisions are now officially ordered by letters. The Resolution also mentions the mandate of the Divisions and the Executive Committee to "produce initial plans for a revised structure of the Commissions" (etc.) by May 2013. (Subsequently there would be slight revisions of the Division names: Div.A would revert to its original name, i.e., that of its predecessor Div.I: "Fundamental Astronomy", and Div.D would be renamed "High Energy Phenomena and Fundamental Physics", both approved at the 2015 GA in Honolulu, along with the new Commissions. The name of Div.F would be changed to "Planetary Systems \& Astrobiology" at the 2018 GA in Vienna.

a revised structure for Commissions, Working Groups and other bodies, to be presented as early as the following EC meeting, in May 2013 (see Fig. 8).

After several presentations and discussions with the GA participants, in particular in the form of lunch-time "Town Hall meetings", Resolution B4 was passed on 30 Aug. 2012, with only a few negative votes and abstentions (see Montmerle 2015). 


\section{The breakthrough: Reforming the Commissions (2012-2015)}

With the decisive help of the Presidents (and the Organizing Committees) of the Divisions, now terminated, and of their Commissions, unchanged, the new Divisional structure was put into place by suitably modifying the IAU Statutes, Bye-laws and Working Rules, also approved in Beijing. In particular, as specified in the Bye-Laws, Divisions were now run by Steering Committees, and not anymore by "Organizing Committees". This was not an innocent change of vocabulary: it really meant that the Divisions now had authority on the conduct of affairs of Commissions. But this authority of course could not be exerted without the active collaboration of the Commissions themselves, which is why Commission Presidents were appointed ex officio members of their relevant Steering Committees. This organization was central to making any Commision reforms acceptable and effective.

The first Division Steering Committees were thus composed of a mixture of members nominated by the EC, exceptionally making use of one of its statutory prerogatives (all the Division Presidents, although some of them had been elected already as Vice-Presidents of previous Divisions, and the Vice-Presidents; but appointed for one term only until the next GA elections), and of elected members (Commission Presidents, representing their Organizing Committees and their Working Groups). Thus, the Commission reform was the result of a close collaboration between the General Secretary and the EC on the one hand, and Division and Commission Presidents on the other. It is important to stress here that, whatever may have been the defects of the now defunct Divisions, the Commission reform would have been impossible without the prior existence of a Divisional structure.

Indeed, while the Division reform had been relatively easy, the hardest task was lying ahead: as already emphasized, the Commissions had a long history of resisting any "topdown" change, mergers or anything else. Even after the Divisions were implemented in 1997, no "spontaneous" merger took place; only one Commission was terminated (in 2000), and four Commissions created, all in 2006, showing a timid opening of the IAU towards the "new astronomy" (52: Relativity in Fundamental Astronomy, the first time since 1925 that a Commission explicitly dealt with Relativity; 53: Extrasolar Planets; 54: Optical \& IR interferometry; and, as mentioned above, Commission 55 on Communicating astronomy with the public).

The tradition of inviting Division Presidents (now reduced to nine, from 12) to EC meetings continued, allowing several face-to-face discussions. But on a day-to-day basis, the exchanges were also facilitated by frequent telecons via the Internet across the globe (implying that some colleagues would have to rise early, others to go to bed late - but it was almost impossible to find a common schedule with Hawai'i, (UTC-10h), especially with respect to the IAU Secretariat in Paris (a $-12 \mathrm{~h}$ time difference !). These nine Presidents were, in the order of Divisions: Sergei Klioner (Germany), David Silva (USA), Mary Kay Hemenway (USA), Diana Worrall (UK), Lidia van Driel-Gesztelyi (France/Hungary/UK), Giovanni Valsecchi (Italy), Ignasi Ribas (Spain), Ewine van Dishoeck (the Netherlands), and Françoise Combes (France).

In turn, the Division Presidents had the heavy responsibility of interfacing with their Steering Committees, in other words with their Commissions. As these Commissions were to be reformed, but were explicitly (and forcibly) involved, they were themselves in turn responsible towards their own members, so that the process, while simple in principle, turned out in practice to be quite delicate, continuing the tradition. However, in the background, after the Beijing GA there was a widespread positive feeling in favour of change, and overall the spirit was that, once the Divisions had been reformed and a momentum triggered, an unprecedented opportunity arose to take bold initiatives for reforming the Commissions. 


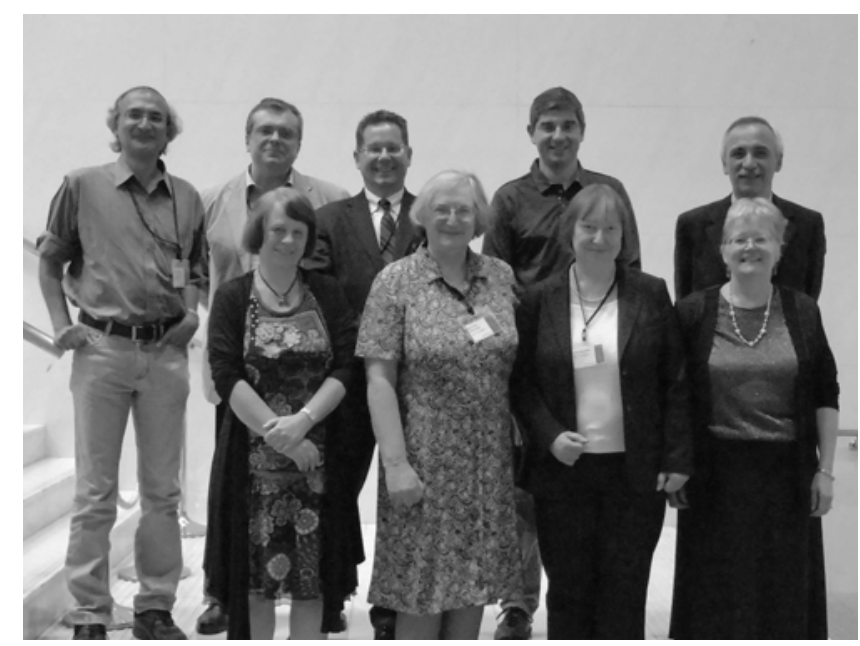

Figure 9. Division Presidents, invited at EC93 in Nara (Japan; 9-11 May 2013), when the historic decision to "reset the Commissions" (i.e., to terminate them and to re-create new ones from scratch) was taken. Back row: Jayant Murthy (replacing Françoise Combes), Sergei Klioner, David Silva, Ignasi Ribas, Giovanni Valsecchi. Front row: Ewine van Dishoeck, Mary Kay Hemenway, Lidia van Driel-Gesztelyi, and Diana Worrall. (Photograph by Hiroko Komiyama, NAOJ.)

Since the goal was to complete the Commission reform in time for the next GA, to be held in Honolulu in 2015, no time could be wasted. According to Resolution B4 voted in Beijing, there was a deadline of the next EC meeting "in May 2013" to "produce initial plans for a revised structure of the Commissions (etc.)".

A new EC took over at the end of the Beijing GA (EC92). Its composition was: N. Kaifu (President), S. Torres Peimbert (President-Elect, Mexico), P. Benvenuti (Assistant General Secretary, Italy), the second-term Vice-Presidents M. Colless, J. Palouš, and M. Rovira, and the incoming Vice-Presidents R. Kraan-Korteweg (South Africa); Xiao-Wei Liu (China Nanjing), and D. Prialnik (Israel).

No time was wasted indeed. Leaving the details out for a future occasion, the main steps may be summarized as follows:

(1) At EC93 (Nara, Japan, 9-11 May 2013), the proposal of the Division Presidents themselves (appearing in Fig. 9; via their spokesperson Ewine van Dishoeck, current IAU President) was a historic one to say the least: to "reset" the Commissions, i.e., to terminate them, and their associated Working Groups, at the Honolulu GA, and to replace them by new Commissions. This was indeed an efficient way to solve the former "Commission merger" issue: no Commission, no merger! This meant that, via their own internal discussions, the Commission themselves had somehow accepted the principle of this future "harakiri" - seppuku in Japanese. (Eventually, some Commissions didn't ask for renewal anyway.) But this also implied a complete change of "regime" for the IAU structures, with a whole new set of Commissions to be created from scratch in one go for the first time since the 32 Standing Committees of 1919 !

Thus, this "top-down" decision was followed by a "bottom-up" process, initiated with the aim to solicit the whole community via a Call for Proposals to create new Commissions. The Call, inspired in its presentation by similar calls routinely issued by various institutions or organizations, would invite the sending of a Letter of Intent, including rules for justifying the need for a Commission, selecting "parent" Divisions to join, explaining selection criteria, giving appropriate deadlines, etc. Submission was to 
take place in electronic form. During the months after the Nara meeting, many discussions, telecons, etc. took place between the General Secretary, EC members and Division Presidents, and also with the ESO Education \& Public Outreach Department, in Garching (for the preparation of the Commission Proposal Form, adapted from ESO Observation Proposal templates). The process timeline and the Call for Proposals were to be approved at the following EC meeting.

(2) The results of these preliminary discussions were gathered in a draft report discussed at EC94 in Canberra (30 Apr.- 2 May 2014), the spokesperson for Division Presidents being Diana Worrall. The Call for Proposals was finalized during the EC meeting. There were many innovations. The main ones were:

- a given Commission may be affiliated to one Division only, or to more than one Division. In that case, one of the Divisions is chosen to be the "primary" Division (then the Commission President is a member of the Steering Committee of that Division only: "Inter-Division" status), or all Divisions are "parents" on an equal footing (then the Commission President seats, or is represented, in all their Steering Committees: "CrossDivision" status), provided a suitable (strong) justification is given in the proposal. This innovation was very important, as it introduced "soft walls" between Divisions, i.e., between member activity areas, while clarifying the Division-Commission relationships and decision process on a flexible, case-by-case basis;

- once the new Commissions are in place [i.e., after the next GA in Honolulu, 2015], all IAU individual members will be asked to join at least one Division (mandatory), and at most three Commissions (optional: contrary to the rule in force since the creation of the IAU, members are allowed not to join any Commission);

- members will have the option of joining, or leaving Commissions at any time (on the condition of notifying the IAU Secretariat, while always staying within the threeCommission limit);

- Commissions are reviewed every three years, and new Calls for Proposals may also be decided jointly by the EC and Division Presidents on a three-year interval (triennium) basis.

Two other paragraphs of the report, related to the proposal selection process, are worthy of note:

- The criteria for selection will be based on scientific excellence, broad geographical distribution of astronomers active in this [Commission] area, quality of proposed activities and other services to the community and/or to society, and timeliness of topic.

- Because the first call for proposals will be for a complete overhaul, simple letters of intent will be invited three months before the proposal deadline. While these will not be binding, they will be reviewed by the Proposal Selection Committee who will have the opportunity to make suggestions to the proposers, which might include the merger of overlapping proposals.

The timeline until Honolulu was very tight, because it had to take into account the quasi-simultaneous elections for the Organizing Committees of the newly selected Commission, followed by those of the renewed Division Steering Committee members, to be organized in time for the GA:

- After finalizing the report with the decisions taken at EC94, have the Call for Proposals ready to be announced to the community by email and posted on the IAU web site by mid-May 2014, i.e., two weeks after the end of the EC meeting;

- Deadline for receiving the Letters of Intent (LoI): mid-October 2014;

- Comments (like a suggestion to merge similar proposals) sent back to proposers: mid-December 2014;

- LoI available on web site: Expressions of Interest by the community, via an indicative vote, deadline Dec. 31; results posted on Jan. 9, 2015; 
- Deadline for Full Proposals: end of January 2015;

- Selection of Proposals: announced shortly after EC95 (end of April 2015);

- Slate of election candidates communicated to IAU Secretariat: end of May 2015;

- Votes open (one-month duration), mid-June; end of votes: mid-July (i.e., two weeks before the start of the GA).

The Commission termination/re-creation plan was announced and explained to the community on 15 May 2014, by a text co-signed by the President and the General Secretary, and posted on the IAU web site: www.iau.org/news/announcements/ detail/ann14008. It started with the following abstract:

This announcement presents the main steps of a plan for reforming the IAU Commissions, prepared by the Division Presidents as a follow-up of the new Division structure approved at the Beijing General Assembly in 2012, recently endorsed by the Executive Committee. This plan includes a call for proposals and selection of new Commissions, a signing-up by individual members for these Commissions, a vote for their Organizing Committees, and the termination of all current Commissions, with the simultaneous creation of the new Commissions by the Executive Committee, at the Honolulu General Assembly in 2015. As a result of this plan, the scientific structure of the IAU will be renewed, expecting in particular that many new Commissions will address the most recent advances in astronomy and astronomical methods. We wish all individual members to be closely engaged in the reform process and in building the new Commission structure. To that effect we have opened an online Commission Reform Forum for feedback to the Executive Committee and to the Division Presidents.

The call itself was issued on 15 June 2014:

www.iau.org/news/announcements/detail/ann14014.

Here are the main events that occurred during the following months until Honolulu. First, the response to the Call for Proposals for Commissions was excellent: 62 Letters of Intent were received, which were followed by a reduced number (47) of full proposals. One factor explaining this reduction was that the LoIs were made public, and subject to an indicative vote in the form of an Expression of Interest:

www.iau.org/news/announcements/detail/ann14029.

The idea was to help the proposers identify the areas worth considering to go on towards Full proposals, and also to obtain a statistically significant estimate of the number of members in the proposed Commissions. Another reason was to identify similar proposals and openly encourage merging, especially in new areas of astronomy. The best example was Gravitational Waves, for which three LoIs were submitted independently, and eventually merged as a basis for a single proposal (more below).

Over 2000 members voted, meaning a participation of $22 \%$. Some Divisions voted with a large participation, like Div. A (62.9\%, see Fig. 10 as an example). The full results were posted on 9 January 2015, at www.iau.org/news/announcements/detail/ann15002, and 47 Full Proposals were submitted in time for the deadline of 31 Jan., 2015.

Then came the proposal selection process, to be finalized at the EC95 meeting in Padua (15-17 April 2015). In order to prevent, as much as possible, personal biases and potential conflicts of interest, it was decided to conduct two evaluations in parallel, by creating a first selection committee composed of Division Presidents only (chaired by the General Secretary), and a second selection committee composed of the EC VicePresidents and Assistant General Secretary (chaired by the IAU President-elect), leaving the President as an independent authority to validate the process, resolve any conflicts and making the final decisions. While having agreed in advance on selection criteria, the two committees adopted their own classification method, with a particular attention to 


\section{LoI Votes Division A Results as of: January $7^{\text {th }}, 2015$}

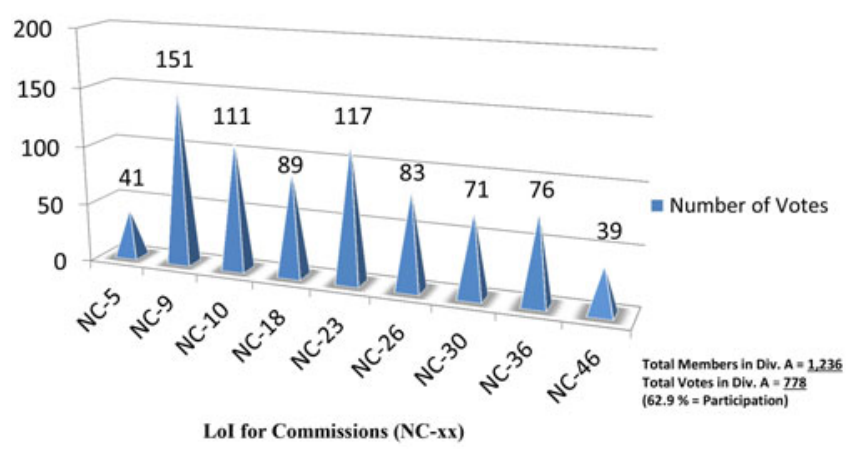

Figure 10. Expression of interest for the proposed Commissions: votes based on Letters on Intent sent to the IAU Secretariat (here the example of Div. A), as posted on the IAU web site (see text). "NC" stands for "New Commissions", numbered in the order of receipt.

the "new winds", i.e., to proposed Commissions that had no equivalent before. Then the two evaluations (summarized by a classical grading of proposals into three categories, A: recommended; B: to be discussed; and C: not recommended) were compared and discussed by all meeting participants, first, EC members and Division Presidents separately, then jointly.

It was comforting for the reliability of the process that both committees generally agreed on "A" and "C" proposals, with sometimes different opinions on "B" proposals, or on examining closely specific requests such as those for "Cross-Division" status. It must be emphasized that the general discussion focused not only on the intrinsic scientific, or societal, interest of the proposals, but also on how the resulting overall Commission structure that would emerge from this selection process would fit the "big picture", i.e., the IAU high-level priorities (in brief: excellence in fields of modern astronomy, leaving room for future evolution; role in education, culture, public awareness world-wide), while keeping a good topical balance. At the end of the process, 35 Commissions were selected, compared with the 40 Commissions in place before the reform.

Once the selection had been made, it was urgent to call individual members to sign up for the new Commissions (now numbered within their Division or primary Division, or marked by an "X" in the case of Cross-Divisions); this was soon done, and the resulting list of "New Commissions" and their respective membership was posted on 19 May 2015: www.iau.org/news/announcements/detail/ann15013.

Then the clock started ticking fast: (electronic) votes were organized to elect the new Division Presidents and Steering Committees (2015-2018), after a slate of candidates had registered to the Secretariat and communicated their statements for the poll. The composition of the incoming Steering Committees was posted on 1 July:

www.iau.org/news/announcements/detail/ann15021,

and similarly, two weeks later, for the new Commission Presidents (ex-officio members of their parent Division Steering Committees) and Organizing Committees (2015-2018), on 15 July: www.iau.org/news/announcements/detail/ann15024. The start of the XXIXth IAU GA in Honolulu (Aug. 3-14) was just two weeks away...

The Divisions had been reformed at the previous GA in Beijing by way of a Resolution mentioning a mandate to reform the Commissions, so it was formally unnecessary to submit a Resolution again to approve the new Commission structure and their Organizing Committees, nor even to organize a vote. Yet, after such an upheaval of the IAU in just two triennia - first, new Divisions, nearly two decades after their creation, then the 
termination of nearly a century of Commissions, succeeded by an entirely new set - the EC nevertheless wanted a full sanction of the new IAU structure by the community, and thus chose to submit it to a vote.

The new Commission structure, and their Organizing Committees, as well as the necessary revisions of the Statutes, Bye-Laws and Working Rules, were unanimously approved on 12 Aug. 2015.

\section{Concluding remarks: a 100-yr old young IAU}

As the IAU approaches its 100th anniversary, it is fair to consider that it is still a "young" (or rejuvenated) organization. As the XXXth GA in Vienna (Aug. 20-31, 2018) has showed, the IAU is an increasingly attractive international organization: in addition to the healthy activities of its nine Divisions, 35 Commissions, and 59 Working Groups, it admitted ten new countries, including nine from Africa and the Middle East, and a new Junior member status was instituted, bringing a total of nearly 1500 new members into the Union. Also, in late 2017 bids to host the XXXIInd GA in 2024 (after the 2021 GA in Busan, Rep. of Korea) were sent to the IAU by no less than seven cities around the world, an unprecedented record. It was only after a very narrow competition that the winner emerged: Cape Town (South Africa), the first GA ever to be held on the African continent.

In order not to lose the memory of the Commissions terminated in 2015, a "Commission Legacy Reports" volume was published, in which the Presidents of the defunct Commissions were asked to summarize their past highlights, covering a long period of time, several triennia when possible (Montmerle 2016).

As for the spirit of the Commission reform, perhaps its most spectacular success is the first detection of gravitational waves, only two weeks after the end of the Honolulu GA, and published a few months later (Abbott et al. 2016), exactly 100 years after the publication of their prediction (Einstein 1916). Of course, the IAU had nothing to do with this extraordinary result, but for the first time in its history a Commission (D1) had been created before the discovery of the cosmic phenomenon it aimed at covering. This resonates as a distant echo of the early creation of Standing Committee No. 1 on "Relativity" by A. Eddington in 1919. Fig. 11 shows the main result of the discovery paper (see caption for some details).

Another striking example is the development of Division C (Education, Outreach and Heritage), the only really new Division founded from the start as an integral part of the Division overhaul in 2012. It had begun on a relatively modest basis, with only three Commissions (but about 20 Program Groups and Working Groups, inherited from the previous divisional structure). Six years later, it has over 2000 members, five Commissions and 25 Working Groups, many of them shared with other Commissions and Divisions. Its activities are also coordinated with those of the current three IAU Offices created since 2011: Office of Astronomy for Development (OAD, Cape Town), Office for Astronomy Outreach (OAO, Tokyo) and Office for Young Astronomers (OYA, Oslo) that runs the International Schools for Young Astronomers (ISYA).

Also, via its Commission C4, it works on behalf of the IAU together with UNESCO to implement the Astronomy and World Heritage Thematic Initiative. An example is the Chankillo observatory of the Chavín and Moche cultures in prehispanic Peru (4th century BC). As illustrated in Fig. 12, the site has been established as a solar observatory, with two main components, a fortified temple overlooking the area, and a series of 13 aligned towers about $1 \mathrm{~km}$ to the south-east, through which the rising Sun may be observed every two weeks - the towers at both extremities corresponding to the solstices (Ruggles 2017). 


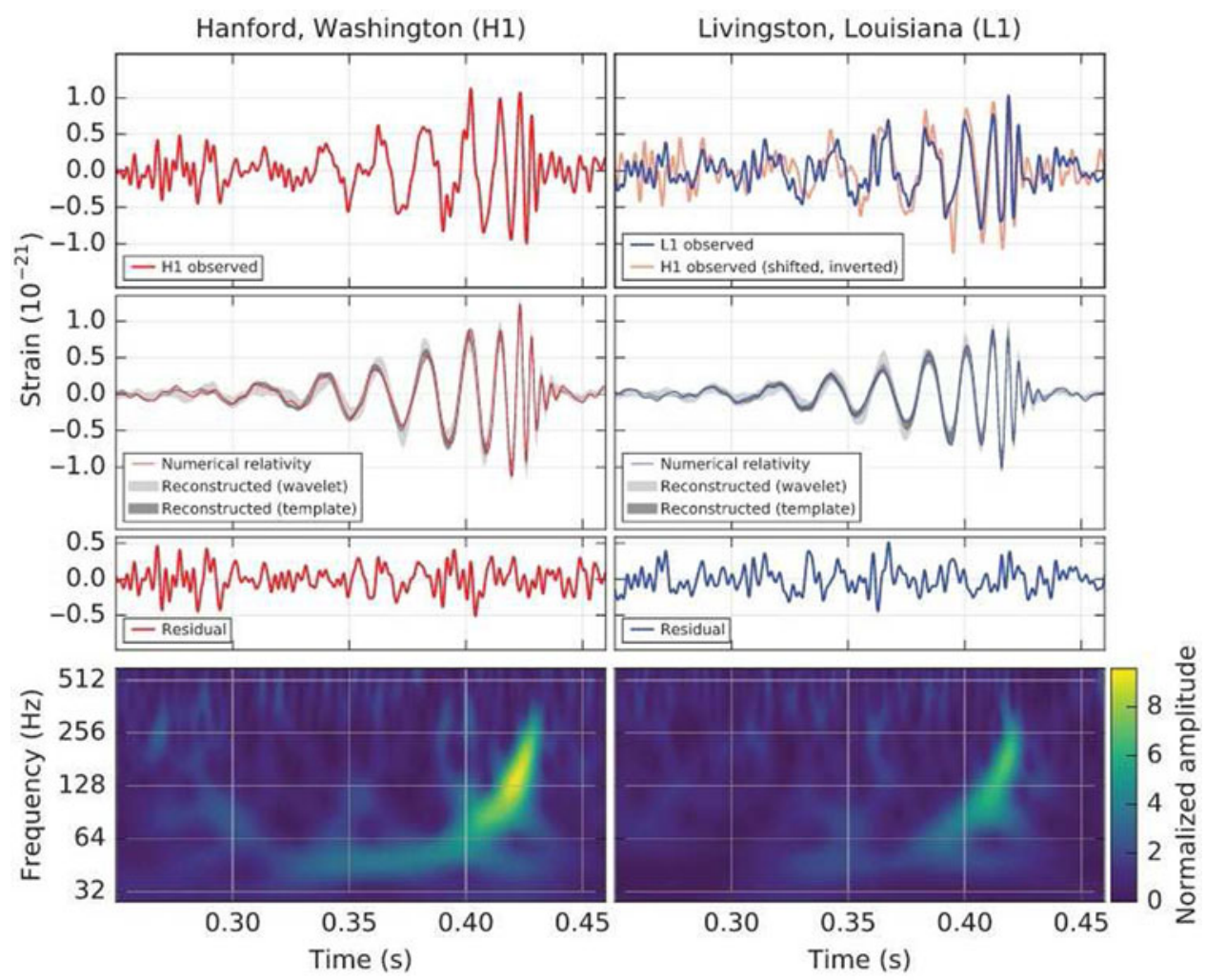

Figure 11. The discovery of gravitational waves, on 15 Sep. 2015 (event GW140915), by the LIGO/Virgo collaboration (fig. from Abbott et al. 2016). The curves are interpreted as being caused by the merger of two black holes of masses $\sim 36 M_{\odot}$ and $\sim 29 M_{\odot}$ in a distant galaxy. The event had been detected simultaneously by the two LIGO Michelson interferometers located $3000 \mathrm{~km}$ apart. This Nobel-prize winning discovery occurred just one month after the creation of Commission D1 "Gravitational Wave Astrophysics" had been approved at the Honolulu GA.

This site, as well as many other astronomical heritage sites across the world, are also described in the UNESCO-IAU web Portal to the Heritage of Astronomy, directly accessible from the IAU home page (www3.astronomicalheritage.net/index.php).

Many other examples could be cited. The IAU appears well equipped today for the next century of astronomical discoveries, and for sharing them with the public worldwide. The program being set up for the 2019 centennial celebrations looks exciting. Stay tuned at www.iau-100.org/events!

\section{Discussion}

Cesarsky: I believe Lo Woltjer's intention was to have the Executive Committee as we know it disappear, to be replaced by a President plus an Assistant General-Secretary plus Division Presidents. But over time the need for an Executive Committee as we have it imposed itself, and little by little the right role of the Division Presidents was defined.

Montmerle: Indeed. I think we have now the right balance between Executive Committee Vice-Presidents (elected at the GA after being proposed by the previous Executive Committee) - as IAU "Ministers" - and Division Presidents (elected by their Division members) as "democratic" representatives of the community. Of course it is also a matter of individuals to reach this balance, but the basis is now firmly established and viewed positively by the community. 

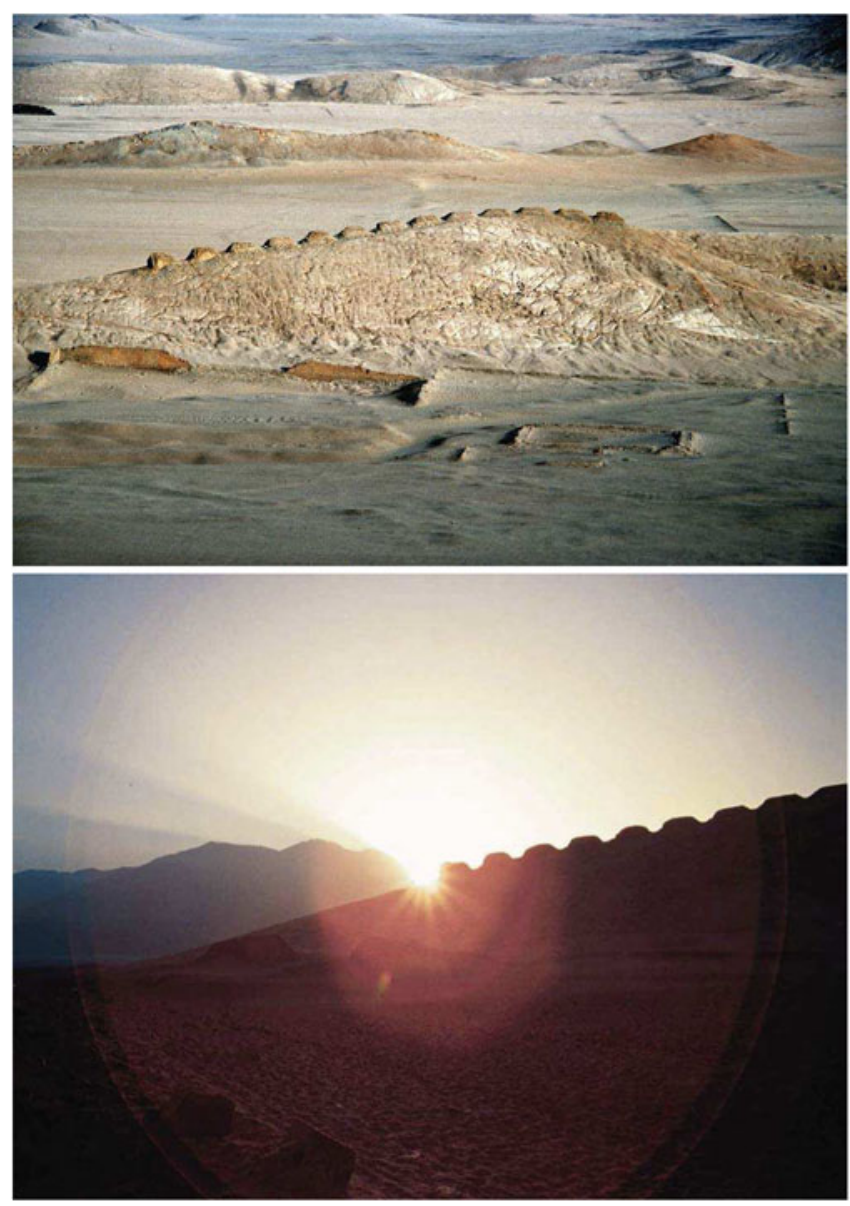

Figure 12. The Chankillo archæological site in the central coast of Peru: a 4th-century BC solar observatory (Ruggles 2017, photographs (C)Iván Ghezzi). Top: The thirteen towers as seen from the fortified temple. Bottom: June solstice sunrise viewed from the western observing point. The December solstice can be similarly viewed at the other end of the construction.

\section{Acknowledgements}

First and foremost, I must acknowledge the fantastic work accomplished by the twelve Division Presidents (2009-2012), and their nine successors (2012-2015), and through them the members of all the other IAU structures that came to an end in 2015. Their good spirit of collaboration with the Executive Committee, their dedication and creativity were essential to achieve the restructuring of the IAU. The successful implementation of the reforms, via the handling of proposals and votes, and in spite of a very tight schedule, owes much to the timeless efforts of Madeleine Smith-Spanier, Database Manager \& Assistant at the IAU Secretariat in Paris, and Mathias André, Web \& Advanced Projects Coordinator, at the ESO Education \& Public Outreach Department, in Garching. Special thanks also to Norio Kaifu, IAU President during my term, for constant support and wisdom during the reform process, and for warm hospitality during my stay in Japan in 2013.

\section{References}

Abbott, B. P., Scientific Collaboration and Virgo Collaboration, 2016, Observation of Gravitational Waves from a Binary Black Hole Merger, Phys.Rev.Lett., 116, 061102 
Adams, W. S. 1949, The History of the International Astronomical Union, Pub.Astr.Soc.Pacific, $61\left(\mathrm{~N}^{\circ} 358\right), 5$

Blaauw, A. 1994, History of the IAU: The Birth and First Half-Century of the International Astronomical Union (Dordrecht: Kluwer), $296 \mathrm{pp}$.

Cock, A. G. 1983, Chauvinism and Internationalism in Science: The International Research Council, 1919-1926, Roy.Soc.J.Hist.Sci., 37, 249

Daston, L. 2017, in Science in the Archives (L. Daston, Ed., U. Chicago Press), p.159

Eddington, A. S. 1919, The Total Eclipse of 1919 May 29 and the Influence of Gravitation on Light, The Observatory, 42, 119

Einstein, A. 1916, Sitzungsber. K. Preuss. Akad. Wiss.: Phys. Math. Kl. 1916 (part 1), 688; Die Grundlage der allgemeinen Relativitätstheorie, Annalen der Physik, vol. 354 (N॰7), 769-822

Isaacson, W. 2007, Einstein, His Life and Universe (New York: Simon \& Schuster), 680 pp.

Lamy, J. (Ed.) 2006, La Carte du Ciel (EDP Sciences, Les Ulis, France), 250 pp.

Montmerle, T. (Ed.) 2015, Reports on Astronomy: Commission Legacy Reports, Transactions of the IAU, Volume 29A (Cambridge University Press), 549 pp.

Montmerle, T. (Ed.) 2016, Proceedings of the Twenty-Eighth General Assembly, Beijing 2012, Transactions of the IAU, Volume 28B (Cambridge University Press), 409 pp.

Ruggles, C. (Ed.) 2017, Heritage Sites of Astronomy and Archaeoastronomy in the context of the UNESCO World Heritage Convention: Thematic Study No. 2 (Paris: ICOMOS/IAU; Ocarina Books Ltd, Bognor Regis, West Sussex, UK), 313 pp.

\section{Appendix A. IAU Information Bulletin 69 (Jan. 1993): Reproduction of the section "Restructuration of the IAU Commissions \& Working Groups"}

[Sentences in italics are my emphasis.]

The proposed restructuration scheme aims at taking into consideration the current main scientific themes of astronomy and the increasing need for international cooperation. Broad scientific themes would imply commissions of a size similar to that of the largest commissions of the Union ( 700 members). Specific tasks and services would then be conducted within smaller entities (Working Groups) whose life span would be limited to the time needed to work out these targets.

In the proposed new structure:

1. There would be larger Commissions with broad scientific themes that reflect the current fields of astronomy. About a dozen of such large Commissions are envisaged. The objectives of the new Commissions should be redefined in the light of the new tasks of the Working Groups (see paragraph 3 below). On this matter, an input is expected from the current Commission Presidents and vice-Presidents. Among these objectives should remain the scientific activities related to the support/selection of symposia/colloquia and GA symposia submitted for consideration by the EC. The organization of scientific meetings at GAs and the setting up of tasks oriented Working Groups and review of their activities.

As a possible example of new Commission structure, one may consider:

- Astrometry

- The solar system

- The Sun

- Stellar dynamics Stellar atmospheres

- Formation, structure \& evolution of stars Interstellar matter

- Galaxy structure \& dynamics

- Galaxies \& clusters of galaxies

- Active galaxies

- Cosmology 
2. There would be a few Commissions on techniques, thus covering a large range of scientific fields:

- Instruments \& techniques

- Radio astronomy

- Astronomy from space

The last two should also be considered as a link between different Unions: the IAU and URSI and COSPAR respectively.

3. All the specific tasks and services would be studied and carried out by Working Groups (WG). In this scheme several current Commissions would become WGs of the EC. There would also be WGs of Commissions. There are presently over $60 \mathrm{WGs}$, but most of them appear fairly inactive. WGs without a task to be accomplished would no longer exist.

The life span of WGs would be more limited than that of Commissions to ensure a real turnover of their activities. These activities would be reviewed at each GA and the WGs would be reconducted for another triennium only if the need of pursuing their current project or to start new activities has been argumented, and if the tasks assigned for the past triennium are well under way. Activities such as encouraging collective investigations, international agreements or participating in standardization processes would now be tasks undertaken by the WGs and not by the Commissions. Since WGs would have to accomplish specific tasks, a budget line should then be created to help financing these activities.

Discussions on the proposed restructuration will be made over the next two years between the Commission Presidents and vice-Presidents and the General Secretary, take place at the next meetings of the EC and at the meeting between the Commission Presidents, vice-Presidents and the IAU officers during the XXIInd GA [The Hague].

Adoption of a new Commission structure at the XXIInd GA for implementation at the XXIIIrd GA [Kyoto] leaves a transition period. A step towards the new structure could be adopted at the XXIIIrd GA: merging between current Commissions. Although the suggestion of Commission merging made during the previous triennium by the General Secretary [D. McNally] did not meet the approval of Commission Presidents/Organizing committees, the concept of mergers is part of a restructuration scheme.

Some possible mergers are suggested on the basis of scientific themes ( ${ }^{\star}$ : appears in more than one merger):

- Time

Commissions 19/31: Rotation of the Earth/Time

- Astrometry \& celestial mechanics

Commissions 4/7/8/20*/24: Ephemerides/Celestial Mechanics/Positional Astronomy/Positions \& Motions of Minor Planets. Comets \& Satellites/Photographic Astrometry

- Physical Studies of Planets \& Satellites

Commissions $15^{\star} / 16$ : Physical Study of Comets, Minor Planets \& Meteorites/Physical Study of Planets \& Satellites

- Solar system minor bodies

Commissions $15^{\star} / 20^{\star} / 22$ : Physical Study of Cornets. Minor Planets \& Meteorites/Positions \& Motions of Minor Planets. Comets \& Satellites/Meteors \& Interplanetary Dust

- The Sun

Commissions 10/12/49: Solar Activity/Solar Radiation \& Structure/The Interplanetary Plasma \& the Heliosphere

- Stellar systems, clusters \& associations

Commissions 26/37: Double \& Multiple Stars/Star Clusters \& Associations

- Formation, structure \& evolution of stars

Commissions 35/42: Stellar Constitution/Close Binary Stars

- Stellar atmospheres \& spectra

Commissions 29/36/45/ Stellar Spectra/Theory of Stellar Atmospheres/Stellar Classification 


\section{Appendix B. Reproduction of EC64 Minutes (Shanghai, 25-28 June 1993): "Commission \& Working Group Matters"}

[Explanatory notes are between square brackets; they are not in the original document. Sentences in italics are my emphasis.]

The General Secretary [J. Bergeron] indicates that restructuring of commissions is going to be discussed in a half a day meeting of the Officers and Presidents and incoming Presidents of Commissions. It is to be mentioned that people who replied would be interested in receiving a summary of the replies to the inquiry. Those who were against would have responded more favorably would the proposal have been written differently, i.e. indicating the aims of the IAU. It seems that they are not against the reform, but that they would have preferred to decide by themselves. They will discuss between themselves and come with a proposal of reorganization.

L. Woltjer [President-Elect] has analysed the replies as follows: 1) several presidents and others ask what is unsatisfactory, 2) any idea of an intermediate stage is dangerous and 3) there is a very broadly concern on how large commissions will function. Answers of presidents have been very different and, that it is difficult to classify those who are pro or con. There is quite a few how reach the same conclusions. Some of them say: if we have to disappear, others have to disappear too. Consequently, it seems dangerous to distribute the replies received. His conclusions are sometimes different from those of the General Secretary. He also stresses that the Executive Committee has to be cautious not to give the feeling that it wants to impose something and that the decision should go to the commissions. It would be catastrophic if such a move eliminates the most prominent members and share the concern about the functioning of large commissions. J. Bergeron, in order to ease the fear of the Presidents, proposes to write a few lines specifying that the EC has initiated the discussions but that it is to the GA to make a decision. L. Woltjer will write a proposal on the basis of his analysis to be discussed before it is sent to Presidents of Commissions, National Adhering Organizations and individuals who replied to the inquiry.

I. Appenzeller [Assistant General Secretary] indicates that the goals of such a restructuring have to be formulated. In his spirit, it is the most important thing to do.

Once again, the problem of very large Commissions is evoked: M. Roberts [Vice-President] wonders what a commission of 1000 persons would mean?

In reply to F. Pacini's [Vice-President] question, the General Secretary informs that up to now, only one mergings has been positively perceived: Commissions 10 \& 12 [See Text, §4]. In the meantime, Commission 49 [Interplanetary Plasma \& Heliosphere], which has been approached to merge with commissions 10 \& 12 has refused.

R. Morton [presumably this is Morton Roberts] summarizes that the proposal as it stands is proposing 10 sections (750 members each) and 25 working groups, i.e. a double structure, which should ensure a good flexibility.

I. Appenzeller thinks it would be useful to put in the statutes that the role of commissions should be reviewed on a regular basis, to which the General Secretary indicates that all ICSU bodies are regularly reexamined. Any proposal to modify the statutes at the moment will make people suspicious. I. Appenzeller stresses that this should not be done before the commissions discussed.

Y. Kozai [previous President] reminds that he reorganized the Tokyo Observatory a few years ago: he encountered exactly the same problems.

A. Boyarchuk [President] has the feeling that our society is not ready to go through a radical change and his himself strongly against to see commissions disappear. He thinks that the problem is how to solve this problem: inputs should be received before the General Assembly, in order to do all the work during the General Assembly. The document exists, and has to be discussed. Time for business session has been restricted, although members may want to discuss this at length. Consequently, he considers that the necessary time has not been given, as it is more a General Assembly business matter than an Executive Meeting one.

The General Secretary is asked to write a new document, with precise questions. This document should be a digest and ask the presidents to propose themselves groupings. They have to coordinate group by group. The General Secretary precises that the presidents will be asked to send their feedback with a deadline, as for other items. 


\section{Appendix C. Document sent to the EC: Divisional structure of the IAU proposed by L. Woltjer (Aug.13, 1994)}

From: L. Woltjer, President Elect

To: Executive Committee IAU

Geneva, 13 August 1994

\section{Restructuring of IAU Commissions: An alternative}

\section{Introduction}

It is not a simple matter to analyze the responses to the proposals for restructuring made by the General Secretary (Sept. 13, 1993) [See Appendix A]. Some presidents favor overall restructuring provided their own commission is left out. Others make a joint proposal, just in case restructuring will occur, but at the same time their individual responses indicate serious reservations. Overall, I conclude that $2 / 3-3 / 4$ of the commission presidents who have expressed an opinion do not favor the proposals for "super commissions"; however, when weighting the opinions by the commission membership the opinions more nearly balance. Whatever views one may have about the merits of specific proposals, it seems difficult to simply do nothing. It has been frequently mentioned that the younger members seem disaffected with the IAU. While a certain lack of interest in commission matters on their part may be rather natural, nevertheless the general perception of the IAU as being an organization mainly preoccupied with "old fashioned" scientific topics, in which the practitioners of the newer subjects have only limited influence, is worrisome. And such opinions prevail not only among the young. In addition, rightly or wrongly, many of the commissions are perceived to be little closed "clubs" that have not much interest in letting new winds blow through. Finally, the discussions of the last three years have raised expectations among those favoring change, and doing nothing will lead to a strong sense of deception.

At the same time it is clear that the Executive Committee cannot and should not try to force extreme changes on the commissions against their will. A solution has to be found which preserves the positive of the present situation, while satisfying those who want renewal.

\section{Proposal}

In view of the various aspects mentioned by the commission presidents and others, and in order to create a flexible mechanism for change which fosters increased interaction, I would propose the following:

I. All of the commissions as presently constituted stay in place and continue their work in the usual way.

II. A divisional structure is introduced to which the commissions may affiliate. These divisions are run by a board composed of:

(a) The commission presidents for divisions with more than 3 commissions;

(b) The presidents and vice-presidents of commissions for divisions with 2-3 commissions;

(c) The president and vice-president plus 3 other members for divisions which are composed of 1 commission.

Thus, each divisional board is composed of 51 persons. These boards elect their own president. The tasks of the divisions or rather of the divisional boards would include:

(1) The endorsement of symposia and colloquia.

(2) The organization of Joint Discussions.

(3) To propose candidates for the Special Nominating Committee (requires a change in the Bye Laws).

(4) To coordinate the activities of the commissions in the division, including the making of proposals for new commissions, proposals for dissolving or combining existing commissions and proposals for working groups.

(5) To advise the EC, in particular by having the division presidents attend the meetings of the $E C$ at the time of the GA. 
With regard to (1), this does not change the role of the commission presidents, except that consultation across commission boundaries will take place, which would seem to be very positive. Item (2) also does not much change the present situation, except, again, that consultation with all adjacent commissions will take place. Of course, this does not in any way exclude meetings sponsored by more than one division. Item (3): Since the divisions would have globally equal numbers of members, it would seem to enhance the fairness in the election process for the EC. Still, as at present, the Nominating Committee would have its role (as specified in Bye-Law 12 a) to ensure that a reasonable balance of nationalities be achieved. Concerning (4), the divisional structure provides a flexible framework for adapting the commissions to evolving circumstances, without creating the feeling that such adaptation is "imposed" from the outside. Finally, with regard to (5), the present meetings of the EC with some forty commission presidents hardly seem to allow effective communication to be established, while a meeting of the 12 member EC with some 12 representative division presidents would be more practical.

An example of a framework for the divisional structure follows:

[The Table of proposed Divisions is given in the Text, Fig. 6.]

\section{Conclusion}

The present proposal would create a high visibility divisional structure with some well defined functions. Moreover, it is a flexible structure: If the proponents of the "super commissions" are right, gradually the divisions may take over from the commissions. If they are wrong, the commissions will continue to flourish in a framework which fosters communication but leaves each commission master in its own house. There is no need to foresee the outcome now, and one can let the situation evolve naturally over the coming decade. Perhaps equally important, one would obviate the need to raise this rather divisive and distracting issue again and again.

The presently proposed divisions would face none of the problems which the "super commissions" would meet. Commission members and their presidents would communicate in the same way as in the past, and so there would be no problems of mass mailings. Also the many commission members who feel more comfortable in smaller, more cohesive units would continue to have these. Nevertheless, more cohesion would be achieved between the related commissions, as well as indirectly between the commissions and the EC.

The triennial "Reports on Astronomy" would continue to be prepared by the commissions as usual with possibly some synchronization by the divisional boards to avoid both duplication and lacunae.

Some direct communication between the divisions and their members might also be useful. The simplest way of achieving this could be through the IAU Bulletin, if each divisional board would have, say, two pages reserved for it in each bulletin; perhaps this might also make the Bulletin more readable.

\section{Appendix D. Proposal for Divisions approved by the EC on Aug.22, 1994, and Divisional structure voted by the General Assembly at The Hague}

Appendix 1/EC 65

\section{Proposal}

In view of the various aspects mentioned by the Commission Presidents and others, and in order to create a flexible mechanism for change which fosters increased interaction, the EC would propose the following:

I. All of the Commissions as presently constituted stay in place and continue their work in the usual way.

II. A divisional structure is introduced to which the Commissions may affiliate. These divisions are run by a board composed of:

a) The Commission Presidents for divisions with more than 3 Commissions;

b) The Presidents and vice-Presidents of Commissions for divisions with 2-3 Commissions; 
c) The President and vice-President plus 3 other Members for divisions which are composed of 1 Commission.

Thus, each divisional board is composed of 51 persons. These boards elect their own President.

The tasks of the divisions or rather of the divisional boards would include:

1. The endorsement of Symposia and Colloquia.

2. The organization of Joint Discussions.

3. To propose candidates for the Special Nominating Committee (requires a change in the ByeLaws).

4. To coordinate the activities of the Commissions in the division, including the making of proposals for new Commissions, proposals for dissolving or combining existing Commissions and proposals for Working Groups.

5. To regularly report and to advise the EC, in particular by having the division Presidents attend the meetings of the EC at the time of the General Assembly.

With regard to (1), this does not change the role of the Commission Presidents, except that consultation across Commission boundaries will take place, which would seem to be very positive. Item (2) also does not much change the present situation, except, again, that consultation with all adjacent Commissions will take place. Of course, this does not in any way exclude meetings sponsored by more than one division.

Item (3): Since the divisions would have globally equal numbers, it would seem to enhance the fairness in the elections process for the Special Nominating Committee. Still, as at present, the Nominating Committee would have its role (as specified in Bye Law 12a) to ensure that a reasonable balance of nationalities be achieved.

Concerning (4), the division structure provides a flexible framework for adapting the Commissions to evolving circumstances, without creating the feeling that such adaptation is "imposed" from the outside. Finally, with regard to (5), the present meetings of the EC with some forty Commission Presidents hardly seem to allow effective communication to be established, while a meeting of the 12 member EC with some 12 representative division Presidents would be more practical.

The Commissions that are at present Commissions of the EC should probably remain so and not become part of a division. This includes Commission 5, 6, 38, 46 and 50 which have very specific functions and which directly relate to the General Secretary.

[The Table giving the Divisional structure submitted to the GA for approval, as included in the proposal, is given in the Text, Fig. 7.] 